\title{
RELIGIOUS SIMILARITY AND RELATIONSHIP QUALITY
}

\author{
A Dissertation \\ presented to \\ the Faculty of the Graduate School \\ at the University of Missouri-Columbia \\ In Partial Fulfillment \\ of the Requirements for the Degree \\ Doctor of Philosophy \\ by \\ ASHLIE M. LESTER \\ Dr. Christine Proulx, Dissertation Supervisor \\ DECEMBER 2013
}


The undersigned, appointed by the dean of the Graduate School, have examined the dissertation entitled

\section{RELIGIOUS SIMILARITY \\ AND RELATIONSHIP QUALITY}

presented by Ashlie M. Lester,

a candidate for the degree of doctor of philosophy,

and hereby certify that, in their opinion, it is worthy of acceptance.

Dr. Christine Proulx

Dr. Lawrence Ganong

Dr. David Schramm

Dr. J. Robert Flanagan 
This is dedicated to my family. Thank you Dan for your support and love. Thank you Mom for your prayers and babysitting. Thank you Joe, Ava, and new baby for keeping me grounded in the present. I love you all so very much. 


\section{ACKNOWLEDGEMENTS}

I would like to thank my advisor and mentor Dr. Chris Proulx. Thank you so much for your support and encouragement, your guidance and feedback. I have grown as a student, a mother, and a professional with your help, and for that I will be forever

grateful. To Drs. Ganong, Schramm, and Flanagan, thank you for your help and support during the last five years. 


\section{TABLE OF CONTENTS}

ACKNOWLEDGEMENTS

ii

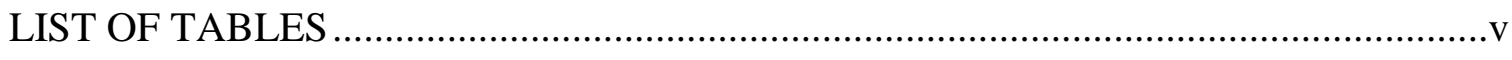

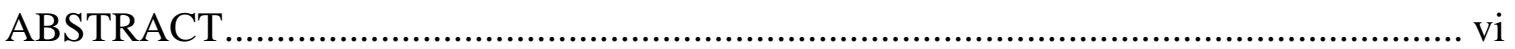

\section{Chapter}

1. INTRODUCTION ..................................................................................

Religion and Relationships

Religious Similarity and Relationship Quality

Relational Spirituality Framework

Joint Religious Activities and Social Support as Mediators

Hypotheses and Research Questions

2. METHODS

Sample

Measures

Independent Variables

Dependent Variable

Mediator Variables

Control Variables

3. PLAN OF ANALYSIS

Measurement of Religious Similarity

Test of Mediation Models

4. RESULTS

Actual Versus Perceived Similarity

5. DISCUSSION 
Implications

Limitations and Strengths of the Current Analysis

Conclusion

REFERENCES

\section{APPENDIX}

1. TABLES. 


\section{LIST OF FIGURES AND TABLES}

Figures

Page

1. Conceptual Model of the Proposed Associations Among Couples' Religious

Similarity, Joint Religious Activities, and Couple's Relationship Quality .16

2. Conceptual Model of the Proposed Associations Among Couples' Religious Similarity, Social Support, and Couple's Relationship Quality .16

Tables

1. Descriptive Statistics

2. Correlations Among Similarity, Joint Religious Activities, Social Support, and Relationship Quality Variables.

3. Unstandardized Estimates, Standardized Estimates, and Significance Levels for Religious Similarity and Relationship Quality....

4. Unstandardized Estimates, Standardized Estimates, and Significance Levels for Joint Religious Activities Mediation

5. Unstandardized Estimates, Standardized Estimates, and Significance Levels for Hypothesized Social Support Mediation

6. Unstandardized Estimates, Standardized Estimates, and Significance Levels for Modified Social Support Mediation

7. Unstandardized Estimates, Standardized Estimates, and Significance Levels for Joint Religious Activities Mediation Model with Respondents' Perceived Similarity

8. Unstandardized Estimates, Standardized Estimates, and Significance Levels for Joint Religious Activities Mediation Model with Partners' Perceived Similarity64

9. Unstandardized Estimates, Standardized Estimates, and Significance Levels for Modified Social Support Model with Respondents' Perceived Similarity

10. Unstandardized Estimates, Standardized Estimates, and Significance Levels for Modified Social Support Model with Partners' Perceived Similarity.... 


\title{
RELIGIOUS SIMILARITY \\ AND RELATIONSHIP QUALITY
}

Ashlie M. Lester

Dr. Christine Proulx, Dissertation Supervisor

\begin{abstract}
This analysis tested social support and joint religious activities as mediators of the relationship between religious similarity and relationship quality, as theorized by the relational spirituality framework. Using a national sample of couples $(N=621)$ from the Portraits of American Life Study (PALS), support for mediation was found only for partners' perceptions of religious similarity. All other hypotheses were unsupported. A discussion of results, implications, and limitations are included.
\end{abstract}




\section{Religious Similarity and Relationship Quality}

Many Americans use their religious and spiritual beliefs to organize their lives and influence their relationships. Most Americans (82.3\%) report that religion is somewhat or very important in their lives (Pew Forum on Religion and Family Life, 2010), and $72.2 \%$ report that religion is very or extremely influential in providing guidance in day-to-day living (National Survey of Youth and Religion, 2003). Religion's influence on marriage has largely been positive. In a meta-analysis of the association between religion and personal relationships (Mahoney, Pargament, Tarakeshwar, \& Swank, 2001), individuals with higher religiosity scores were found to have happier, more stable marriages compared to those with lower religiosity scores. These connections were fairly consistent across studies (for an exception, see Booth, Johnson, Branaman, \& Sica, 1995), suggesting a positive association between religious beliefs and relationship outcomes. However, the associations tended to be weak in magnitude and to rely on one- or two-item assessments of religiosity, usually related to frequency of worship service attendance or importance of religion to the individual (Mahoney et al., 2001). Such limited assessments are prone to be unreliable, do not address the full spectrum of religiosity or the mechanisms by which religion influences relationships, and tend to focus on the individual's, not couple's, religiosity or relationship quality.

Religious homogamy, or the similarity of partners' denomination or levels of religiosity, is related to relationship outcomes. Couples in which partners share the same religious affiliation, compared to those who do not, are less likely to experience divorce (Lehrer \& Chiswick, 1993) and relational conflict (Chinitz \& Brown, 2001; Curtis \& Ellison, 2002), and are more likely to report high levels of marital adjustment (Schramm, 
Marshall, Harris, \& Lee, 2012). This dichotomous indicator, however, does not capture partners' similarity in various other, potentially important, dimensions of religiousness, such as behavior, salience, or belief (Mahoney et al., 2001).

More recent research partially addresses this gap by examining similarity in specific behavioral and attitudinal indicators. Similarity in rates of attendance (Call \& Heaton, 1997; Vaaler, Ellison, \& Powers, 2009), conservative theological beliefs (Vaaler et al., 2009), and communication about religious issues (Williams \& Lawler, 2003), rather than denominational affiliation, have been significant in predicting relationship stability and satisfaction. These findings indicate that dyadic and multidimensional assessments of couples' religiousness may be a more reliable and accurate predictor of relational outcomes than individual religiousness. However, most findings relied on individual reports and only one or two dimensions of religious similarity. This has led to a correlation-rich, explanation-poor body of knowledge about religion and relationships. In sum, it is largely unknown why these associations exist between religious similarity and relationship outcomes.

Given these previous findings and limitations in the literature, future research on religious homogamy and relationship outcomes should focus on inclusive measurement and mechanisms that link homogamy and relational outcomes. First, most scholars agree that the experience of religion is comprised of behavior, attitudes, and beliefs. Assessing a couple's similarity or dissimilarity in religious behaviors, beliefs, and attitudes—not just denominational affiliation — is sensitive to this multi-faceted nature of religion and provides a more complete picture of religious homogamy. Second, to move beyond correlational findings and to uncover a finer-grained picture of religion and relationships, 
research must test theoretically-based processes by which religious homogamy influences intimate relationships. Doing both will provide a more nuanced and complete understanding of the intersection of religion and intimate relationships. Thus, in the current study, we focus on couples' religious similarity by using both partners' reports of their religious beliefs, behaviors (i.e., attendance, prayer), and salience. We also test whether two mechanisms - joint religious activities and social support — mediate the association between religious similarity and relationship quality.

\section{Religion and Relationships}

\section{Religious Similarity and Relationship Quality}

The principle of homogamy suggests that individuals are attracted to and have better relationships with people who are similar to them (for a review, see Karney \& Bradbury, 1995). Theoretically, similar people are attracted to each other because sharing a worldview, values, and goals with a loved one is validating and, therefore, rewarding. Indeed, similarity in demographics, attitudes and values, and personality has predicted relationship satisfaction and affect (Gaunt, 2006). Couples' religious similarity is typically operationalized by comparing partners' individual religious affiliation: Either they match (same-faith) or they do not (different-faith). This single indicator has been used to predict relationship satisfaction (Heaton \& Pratt, 1990), conflict, and stability

(Chinitz \& Brown, 2001). However, much like global indicators of individual religiosity (e.g., frequency of worship service attendance), these correlations are weak, do not illuminate the mechanisms leading to such outcomes, and have resulted in mixed findings. For example, in a sample of 2,945 first-time married couples, denominational homogamy or heterogamy did not significantly predict frequency or type of marital 
conflict (Curtis \& Ellison, 2002). Further, rates of marital dissolution did not differ for those who were of the same denomination compared to those who were not $(74 \%$ of the sample; Vaaler, Ellison, \& Powers, 2009). In light of this, scholars have attempted to measure more sensitively religious similarity (or dissimilarity) by including differences between partners in frequency of religious behaviors (e.g., attendance, prayer), theological beliefs, and religious salience.

Religious behavior similarity. Partners' rates of attendance at religious services have been significantly associated with relational outcomes. Heaton (1984) found that, in a national dataset, husbands' and wives' religious attendance significantly and positively predicted relationship satisfaction, and, perhaps most notably, once differences in attendance were accounted for, same- or different-faith status no longer predicted marital satisfaction. Additionally, dissimilarity in attendance has been linked to poor relational outcome. Vaaler et al. (2009) found that husbands who attend religious services more frequently than their wives had a greater risk of divorce than partners who attended at the same rate. Among denominationally heterogamous couples, those with mixed attendance (i.e., one partner attended more than the other) had the highest risk of divorce, compared with denominationally homogamous, high attendance couples (Heaton \& Pratt, 1990). Attending services together, however, appears to reduce the risk of divorce for differentfaith couples (Vaaler et al., 2009). Finally, Curtis and Ellison (2002) found no differences in frequency of conflict between same- and different-faith couples, but differences in attendance (i.e., one partner attends more frequently than the other) significantly predicted more frequent conflict for both same- and different-faith couples. 
Taken together, these findings point to the importance of partners' behaviors, above and beyond denominational affiliation.

Frequency of prayer and frequency of reading religious texts have also been associated with positive relational outcomes (Mahoney et al., 2008), including high levels of marital adjustment (Gruner, 1985), and openness and decreased hostility to partner during conflicts (Butler, Stout, \& Gardner, 2002). In a qualitative study of religious couples, Butler, Gardner, and Bird (1998) found that couples who prayed regularly described their marriage as a triad — two spouses and a deity. The direct experience of the deity in the marriage related to decreased negativity in conflict, and promoted perspective-taking and taking responsibility for self-change. Similarly, Beach and colleagues (Beach, Fincham, Hurt, McNair, \& Stanley, 2008) proposed that prayer may be related to relationship outcomes because prayer can (a) encourage perspective-taking in times of conflict or stress; (b) interrupt patterns of negative interaction, affect, or cognition; (c) be a tool for self-soothing and relaxation; and (d) be a conversation with a supportive entity (e.g., God, Allah). Despite the evidence that couples' prayer influences relational outcomes, the similarity of spouses' frequency of prayer has not been addressed explicitly in the literature.

Belief homogamy. Few studies have assessed theological beliefs specific to religious teachings. However, Biblical literalism (also termed theological conservatism or religious authority) is an orientation toward religious texts that has emerged as influential to relationship outcomes (for an exception, see Heaton \& Pratt, 1990). Defined as the extent to which individuals believe in the inerrancy of their religious texts (Read \& Eagle, 2009), differences between partners' Biblical literalism scores 
significantly predicted marital stability (Vaaler et al., 2009) and conflict (Curtis \& Ellison, 2002). Specifically, wives who held more conservative and literal views of the Bible than their husbands were at increased risk of divorce (Vaaler et al., 2009), and any differences in Biblical literalism between partners predicted more frequent conflict, particularly conflict about finances and household chores (Curtis \& Ellison, 2002). These differences in beliefs may indicate differences in worldview or values, which may create or perpetuate conflict, make it difficult to compromise, reduce confidence in decisions about the family as moral or right, and, ultimately, negatively impact perceptions of relationship quality (Curtis \& Ellison, 2002; Kalmijn, 1998).

Salience homogamy. Religious salience is defined as "the importance individuals attach to their religious values and experiences" (Mason \& Spoth, 2010, p. 684), and it has been operationalized many different ways (e.g., "How religious are you?" "How important is religion to you?" "How important is religion in your identity?" "How influential is religion in life decisions?" "How important is religion in everyday life?"). Individual religious salience has been positively linked with the likelihood of being in a denominationally homogamous marriage, having a consistent religious identity (Winter, 2002), and marital satisfaction (Mahoney et al., 2001).

Couple similarity in religious salience appears important, as well. In a study of 228 married Seventh-Day Adventists, Dudley and Kosinski (1990) found that marital adjustment was predicted by the similarity of religiousness ("my spouse is more, less, or equally religious than I'). Inter-church couples reported greater differences in religious salience (as measured by a religious differences scale, which included items assessing the importance of prayer, religious service attendance, and religious text) than same-church 
couples (Williams \& Lawler, 2003). Religious differences, in turn, were inversely related to marital satisfaction (Williams \& Lawler, 2003). Myers (2006) found that marital happiness and stability are negatively affected when spouses perceive differences in how they and their partners are influenced by religion (i.e., if one partner perceives religion is either more or less influential to the partner than to him- or herself). Similarly, in a sample of first-married and remarried newlywed couples, marital adjustment scores were higher for spouses in a first marriage who reported they were both religious, compared to spouses who were both not at all religious and to couples in which one spouse was more religious than the other (Schramm et al., 2012). In remarried couples, spouses who reported they were both religious had higher marital adjustment scores than when wives were more religious than husbands, or when both spouses reported being not religious.

Although couples' and individuals' levels of similarity on religious behaviors, beliefs, and salience have been individually linked with several relationship outcome measures, they have not been considered simultaneously as indicators of religious homogamy. Doing so may capture the multidimensional nature of religious experience and more sensitively measure religious similarity. In turn, this holistic view of religious similarity may more accurately predict not only relationship outcomes, but the spiritual mechanisms that lead to such outcomes.

\section{Relational Spirituality Framework}

The relational spirituality framework (Mahoney, 2010) was used to ground the current study. Because this framework is based on Mahoney and Pargament's (2002) definitions of religion and spirituality, those will be briefly defined here. Spirituality is defined as a search for the sacred, divine, or transcendent. The words sacred, divine, and 
transcendent are used rather than a deity (e.g., God, Allah) first, to include both theist and non-theist belief systems, as these words describe the core element of God, transcendent reality, and the like. Second, they are used because the sacred can be experienced outside of an external deity. For example, a time, a place, or a relationship may become sacred if imbued with divine qualities (e.g., one's marriage might be described and experienced as holy or a blessing). In other words, spirituality is the direct experience of the sacred, wherever and however it may happen.

Religion is defined as a "search for significance in ways related to the sacred" (Mahoney, 2010, p. 810). In short, it encompasses the practices and functions of organized religion. Some theorize that religion has at its core the function of fostering spirituality, but it also includes other functions, like social support and prescriptions of behavior, and practices, like prayer, attendance, tithing, and fasting (Hill \& Pargament, 2003; Shahabi, Powell, Musick, Pargament, Thorenson, Williams et al., 2002; Zinnbauer, Pargament, Cole, Rye, Butter, Belavich et al., 1997). Religion and spirituality, therefore, have been conceptualized as distinct, yet closely related, concepts that cannot be reduced to psychological processes (Hill \& Pargament, 2003; Seidlitz, Abernathy, Duberstein, Evinger, Chang, \& Lewis, 2002). Because the mechanisms detailed in this framework can occur within and outside of an organized religion, they are termed spiritual mechanisms.

The relational spirituality framework acknowledges that spiritual and religious experiences inherently involve relationships, and indeed it was designed to capture the associations between religion and family life. To do this, Mahoney identified three stages of family relationships: "(a) formation, or the creation and structure of family 
relationships; (b) maintenance, or processes to conserve family relationships; and (c) transformation, or fundamental changes in the structure or processes of distressed family relationships" (2010, p. 807).

Intersecting with the three stages of family relationships are three mechanisms by which religion and spirituality may influence these relationships. First, each family member may have a relationship with God, the divine, or transcendent reality. The discovery and maintenance of this relationship, often through prayer or meditation, becomes spirituality itself (Pargament \& Mahoney, 2002). This relationship can be a powerful attachment. Some may form this connection to a specific deity in line with a particular religious belief; for others, the connection may be to a supernatural force. Individuals may turn to this relationship for support in stressful times; this can be both adaptive (e.g., benevolent reappraisals) and maladaptive (e.g., triangulating God during marital conflict; Pargament, 1999).

Second, family relationships themselves may become spiritual. This occurs either through a cognitive process of ascribing sacred qualities to the relationship (i.e., sanctification) or through shared behavior, such as joint religious attendance, dialogue about spirituality, or joint prayer. Both cognitive and behavioral processes render the relationship a place to experience the transcendent.

Finally, individuals and their family members may have relationships with spiritual communities. Spiritual communities include formal and informal social networks of fellow believers. For those who are affiliated with a particular denomination, the spiritual community would include their congregations; for those who are not affiliated and seek spirituality through other means, spiritual community includes like- 
minded individuals with whom the person or couple interacts. Limiting spiritual communities to congregations excludes those individuals who are not affiliated and excludes social contacts who may be fellow believers, but not co-congregants.

The current study, with its focus on already-established couples and their relationship quality, falls squarely into the maintenance stage of family relationships. Based on Mahoney's (2010) relational spirituality framework, joint religious activities and social support are the spiritual mechanisms by which we hypothesize couples' religious similarity will influence relationship quality.

\section{Joint Religious Activities and Social Support as Mediators}

Joint religious activities. Defined by Mahoney and colleagues (1999) as religious experiences shared by both partners, joint religious activities encompass experiences both formal (e.g., attendance at worship services, rituals) and informal (e.g., religious discussions, home-based routines). Joint religious activities can influence relationships in several ways. First, shared experience, religious or not, improves relational outcomes (Strong \& Aron, 2006). Second, sharing one's individual religious and spiritual self with one's partner may bond the couple and promote intimacy (Kalmijn, 1998; Williams \& Lawler, 2000). Third, joint religious activities may be a way to express similarity, reinforce the couples' worldview, and build confidence in the validity and morality of their decisions (Kalmijn, 1998). Fourth, joint religious activities may help religiously dissimilar couples to find points of similarity and to understand and respect the partners' beliefs. Williams and Lawler (2000) found that religious discussion and attending worship services together were particularly helpful for long-term married couples who were of different faiths at the time of courtship. Couples reported that 
sharing religious experiences and the subsequent discussions allowed them to identify and emphasize their similarities in belief (e.g., emphasizing their Christian marriage, versus a Catholic-Protestant marriage). Fifth, joint religious activities may transform the relationship into a place to have a direct experience of the divine. This may render partners more likely to invest their resources in and protect their relationship (Mahoney et al., 1999).

There exists empirical support for the role of joint religious activities in a variety of relationship outcomes for both religiously similar and dissimilar couples. Joint religious activities predicted better problem-solving in conflict (e.g., more collaboration, fewer stalemate strategies, and less verbal aggression), greater marital satisfaction, and fewer conflicts (Mahoney, Pargament, Jewell, Swank, Scott, Emery, \& Rye, 1999). Ellison, Burdette, and Wilcox (2010) found that the shared religious activities of joint prayer or other in-home religious rituals significantly predicted relationship quality in a national data set, even after controlling for denominational homogamy. Williams and Lawler (2003) found that joint religious activities - for both same-church and interchurch couples_-significantly predicted marital satisfaction. Both inter- and intra-faith couples used their religious beliefs as a point of entry for discussion-similarities in beliefs, in the case of same-faith couples, and differences in beliefs for inter-faith couples. These discussions - a form of joint religious activity-led to deepened intimacy (Heller \& Wood, 2000) and greater marital satisfaction (Williams \& Lawler, 2000; Williams \& Lawler, 2003). The literature, therefore, suggests that joint religious activities might mediate the association between religious similarity and relationship outcomes. 
Social support. Social support is the tangible, emotional, and spiritual benefits from belonging to a social network (Krause, 2008). It has been assessed in a variety of ways, ranging from a single item ("How often do people in your church help you out?" Ellison, Boardman, Williams, \& Jackson, 2001) to a multi-dimensional scale assessing type and frequency of support, type of contact (i.e., face-to-face or virtual), and proximity of social contacts (Krause, 2002). Social support has been assessed for members of an individual's social network, regardless of the social setting or nature of the relationship (Eliasson, Taylor, \& Lloyd, 2005), as well as for only church-based networks (Krause, 2002). Most studies limit social contacts studied to those the individual feels closest, or to an arbitrary number of contacts. Overall, it appears that couples' religious similarity influences the level of social support they receive, and social support in turn predicts relationship quality.

Social support appears to be influenced by couples' religious similarity, as similarity is associated with (1) frequent and joint religious attendance, (2) congregational and family support, and (3) comfort in partners' social networks. First, couples of the same religious denomination attend religious services more frequentlyand attend jointly— than couples of different denominations (Mahoney, 2010). Because the church institution itself is integrated into the wider community, participants who attend worship services regularly tend to have wider and more varied social networks, and receive more types of social support than those who are infrequent attenders (Ellison $\&$ George, 1994). Religiously similar couples therefore may be exposed to a wider variety of people of similar faith and to a greater pool of resources than religiously dissimilar couples. Religiously similar couples, compared to religiously dissimilar 
couples, have more social contacts in common (Kearns \& Leonard, 2004), and attending services as a couple was associated with greater joint social contacts (Burger \& Milardo, 1995). This overlap in partners' social networks has been linked with more social support for relationships and, ultimately, with relationship stability (Kearns \& Leonard, 2004) and satisfaction (Burger \& Milardo, 1995).

Religiously similar partners tend to have similar patterns of activating their social networks, particularly how frequently they contacted friends and family, attended social gatherings, and visited restaurants (Kalmijn \& Bernasco, 2001). The integrated social lives led by partners in religiously similar relationships may promote a couple identity, restrict opportunities to meet alternative partners (which increases relationship commitment; Miller, 2008), and reinforce values and enforce behavioral norms that are consistent with the couples' attitudes and beliefs, particularly regarding family issues (Kearns \& Leonard, 2004).

Second, religious similarity is associated with congregational and family support. Relationships that are congruent with religious teachings and beliefs may engender more support from the religious community than those relationships that are incongruent (for examples, see Sorensen, Grindstaff, \& Turner, 1995, and Taylor \& Chatters, 1988). Because most religions promote endogamy (i.e., coupling within the group), same-faith relationships may be viewed as consistent with the teachings and may receive more congregational support than those in inter-faith relationships.

Social support from family, regardless of family's affiliation, may also be influenced by couples' religious similarity. In a qualitative study of interfaith couples and weddings, Kaplan (2004) found that individuals experienced pressure from their 
families to have same-faith unions. This pressure was both explicit (e.g., being told directly not to marry the different-faith partner) and implicit (e.g., pointing out potential same-faith partners after the decision to wed had been made). The decision to marry was frequently met with ambivalence by the family, rather than with excitement or enthusiasm, which strained the relationship between parents and adult children and, in some cases, between the partners. Many reported that their interfaith union caused distrust and tension in the relationship and that their parents felt hurt and rejected. This, for many, led to reducing time spent with extended family, a reduction in emotional support from family members, and, for some, a complete cut-off from the family.

Finally, the comfort individuals feel in the presence of their partners' family and congregation networks may also influence social support received. Religiously different partners reported feeling like an outsider, unsupported, or awkward, leading to limited contact with extended family and the congregation (Kaplan, 2004; Williams \& Lawler, 2000). This may leave some religiously dissimilar couples without supportive social networks. Conversely, the relative comfort felt by religiously similar couples may foster greater participation and integration in family and congregational networks, thus leading to more opportunities for support. Religious similarity, therefore, influences couples' social support through frequent and joint religious attendance, congregational and familial support, and comfort in partners' social networks.

Social support, in turn, influences relationship quality. When social support is sought by partners, the feedback from integrated or joint social networks is likely to be consistent with the couples' beliefs and values, which may improve confidence in decisions made about the family (Kalmijn \& Bernasco, 2001). Consistent with this idea, 
Julien and Markman (1992) suggested that one partner's social support benefits not only the individual, but also the couple. Indeed, Burger and Milardo (1995) found that social support predicted marital satisfaction, and Pargament and colleagues (1998) found it predicted better relational outcomes following a crisis or family transition.

\section{Hypotheses and Research Questions}

Because of the relational nature of the experience of religion and spirituality, and because most religious teachings include prescriptions for family relationships, this study focuses on the dyadic nature of religion and relationships through religious similarity, joint religious activities, social support, and relationship quality. Consistent with the relational spirituality framework (Mahoney, 2010), religious similarity may influence relationship quality through joint religious activities and social support. Religious similarity is associated with both joint prayer and religious discussion, and with greater social support received by congregations and family networks. Joint religious activities and social support, in turn, have been associated with positive relational outcomes. Given previous research, we proposed the following hypotheses:

H1: Religious similarity will be positively associated with couples' relationship quality.

$\mathrm{H} 2$ : Joint religious activities will mediate the relationship between religious similarity and relationship quality.

H3: Social support will mediate the relationship between religious similarity and relationship quality. 


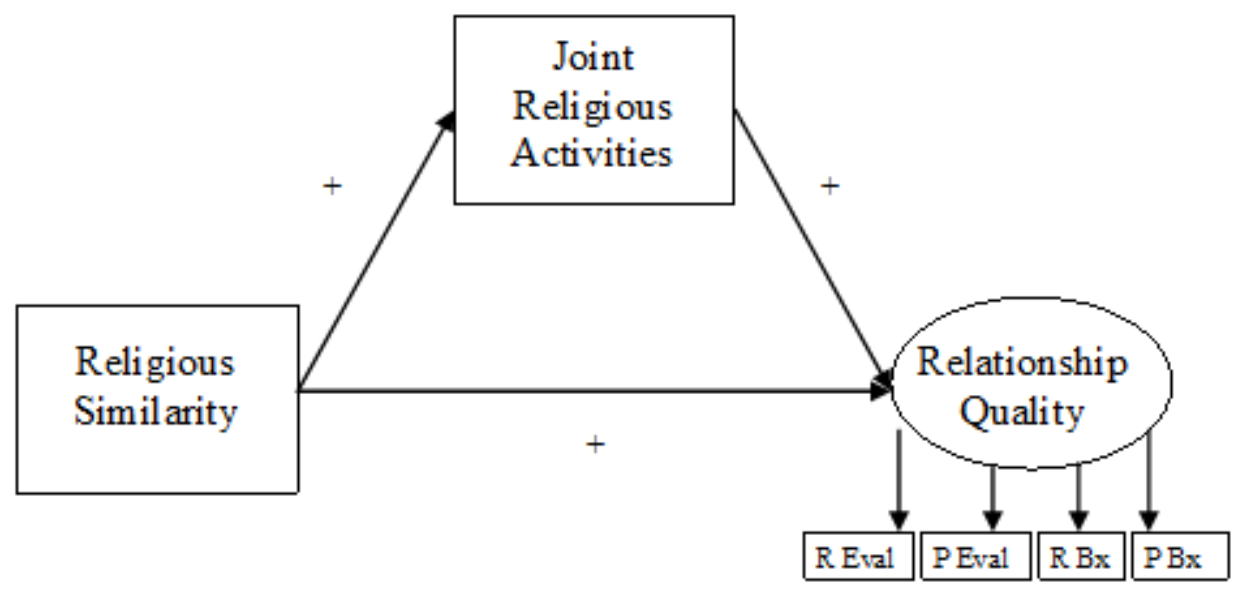

Figure 1. Conceptual model of the proposed associations among couples' religious similarity, joint religious activity, and couples' relationship quality.

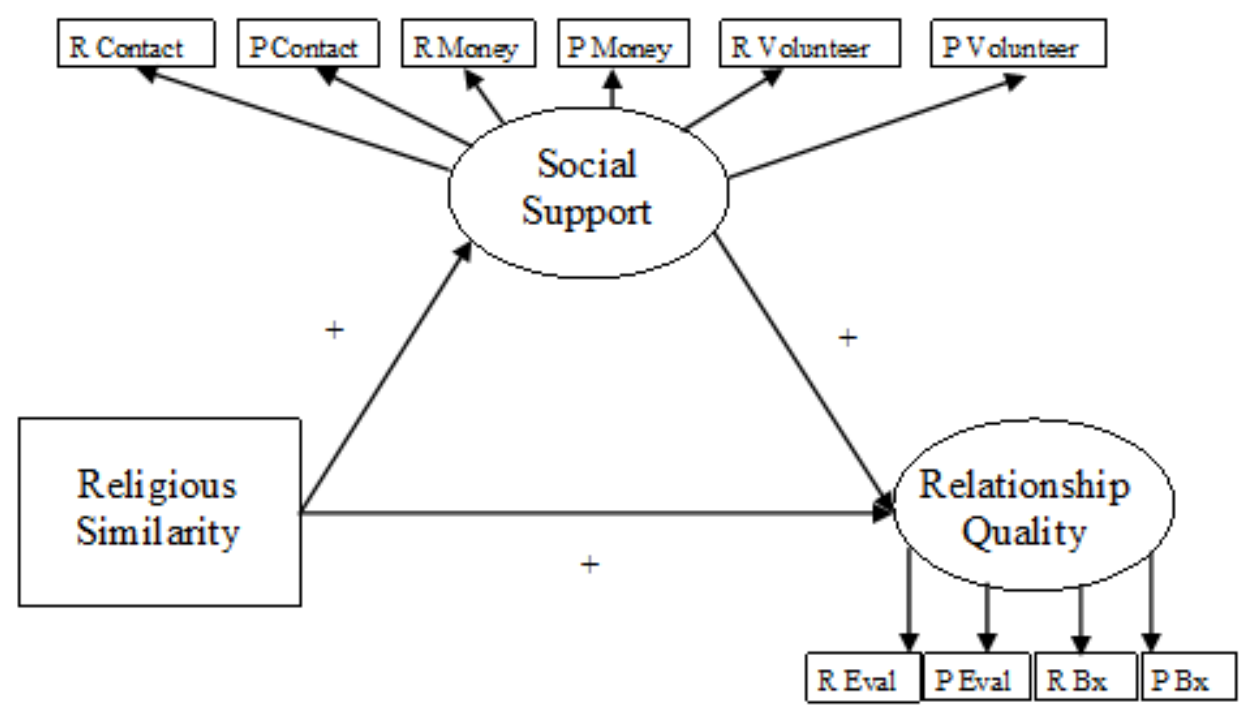

Figure 2. Conceptual model of the proposed associations among couples' religious similarity, social support, and couples' relationship quality. 


\section{Methods}

\section{Sample}

The current study used the first wave of the Portraits of American Life Study (Emerson \& Sikkink, 2006). This study was designed to provide nationally representative data, with emphases on religious and ethnic diversity. Participants were identified by a process of random selection: From purchased lists of home addresses, zip codes were selected and cross-referenced with the 2000 Census to adequately represent the diversity of the United States. Within these zip codes, postal carrier routes - and 41 addresses on each—were randomly selected. Individuals at these addresses were contacted by a letter describing the study in advance of an in-person screening interview. Full interviews were completed in-person, with questionnaires being administered with a laptop computer. Interviews took approximately 75 minutes to complete, and participants were given a $\$ 50$ incentive for completion. Of the 10,320 addresses selected, 2,610 target respondents (51.8\% female) completed the interview in 2006 . Respondents' partners (i.e., spouses or cohabiting partners) were invited to fill out paper and pencil questionnaires independently; after completing and returning the questionnaires, partners were mailed a $\$ 15$ incentive check. This analysis will use only the dyadic data $(n=621$ couples).

Of the primary respondent sample $(N=2610), 70.4 \%$ reported their race/ethnicity as Caucasian, $11.1 \%$ as Black, $13 \%$ as Hispanic, $4.7 \%$ as Asian, and .7\% as Native American. Most of the primary respondents earned a high school diploma (or equivalent) or less $(63.3 \%)$, with $25.5 \%$ reporting a Bachelor's degree or some college, $10.4 \%$ reporting a Master's degree or higher, and .8 reporting other, don't know, or refused. 
When reporting on total household income, $37 \%$ of respondents earned less than $\$ 30,000$, $30 \%$ earned $\$ 30,000$ to $\$ 59,999,21 \%$ earned $\$ 60,000$ to $\$ 99,999$, and $12 \%$ earned over $\$ 100,000$. Most primary respondents identified as Christian (52.2\%), with 26.5\% Roman Catholic, $9.7 \%$ spiritual but not committed to a particular faith, $2.6 \%$ agnostic, $2.2 \%$ not giving religion much thought, $1.5 \%$ Jewish, $1.4 \%$ Hindu, $1.1 \%$ Buddhist, $1.1 \%$ atheist, $.8 \%$ other, $.5 \%$ Muslim, and $.4 \%$ Latter-day Saints or Mormon. In terms of marital status, $57.2 \%$ reported being married, $6.9 \%$ reported living with an unmarried partner, $4.8 \%$ were widowed, $8.9 \%$ reported being divorced or having a previous marriage annulled, $2.4 \%$ were separated, and $19.8 \%$ were never married. The median age of the primary respondent sample was 42 , with $21.3 \%$ between 18 and 29 years old, $28.5 \%$ between 30 and 44 years old, $28.9 \%$ between 45 and 59 years old, $15.8 \%$ between 60 and 74 years old, and $5.4 \% 75$ or older.

The respondent subsample $(n=621)$ was primarily Caucasian $(67.1 \%)$; through oversampling, African-Americans comprised 9.2\% of the sample, and Hispanics $13.8 \%$, Asians 9.3\%, and Native Americans .5\%. Most had earned a high school diploma (or equivalent) or less (55\%), whereas $30.2 \%$ earned some college or a Bachelor's degree, $14.2 \%$ earned a post-college degree, and .6\% refused or reported other. When reporting on total household income, $21 \%$ of respondents earned less than $\$ 30,000,30.7 \%$ earned $\$ 30,000$ to $\$ 59,999,27.7 \%$ earned $\$ 60,000$ to $\$ 99,999$, and $20.6 \%$ earned over $\$ 100,000$.

The respondent subsample was predominantly Christian (51.0\% identified as Protestant; $27.9 \%$ as Roman Catholic). The remaining respondents identified as spiritual but not religious $(8.1 \%)$, agnostic $(2.4 \%)$, not giving religion much thought $(2.4 \%)$, Jewish (1.9\%), Hindu (1.4\%), Buddhist (1.9\%), Atheist (1.0\%), Muslim (.5\%), or Latter- 
Day Saints (.2\%). Most respondents and their partners share the same religious faith tradition (62.2\%). Most of the respondent subsample (61.2\%) reported religion or religious faith was very, extremely, or most important in their lives; $27.6 \%$ reported somewhat important, $11.1 \%$ reported not at all important, and .4\% didn't know or refused. Almost half (45.6\%) reported being currently involved in, affiliated with, or a member of a religious congregation. Most of the respondent subsample was married (89.9\%), with 9.7\% reporting living with an unmarried partner, and .5\% reporting as never married. The mean age was 48 years old, with $13.5 \%$ between 18 and 29 years old, $33.8 \%$ between 30 and 44 years old, $27.7 \%$ between 45 and 59 years old, $19.4 \%$ between 60 and 74 years old, and $5.6 \% 75$ or older.

The partner subsample ( $n=621)$ was comparable to the respondent sample: $42.1 \%$ earned a high school diploma (or equivalent) or less, $41.9 \%$ earned some college or a Bachelor's degree, $13.2 \%$ earned a post-college degree, and $2.7 \%$ reported other. Race/ethnicity, gender, and age were not assessed in the partner questionnaire. Although individual income was assessed, I used the respondents' reports of household income in the analysis. Most partners identified as Protestant (41.7\%), with the remaining partners identifying as Roman Catholic (29.6\%), spiritual but not religious (12.9\%), don't think about religion (4.1\%), agnostic (2.9\%), other (2.4\%), Jewish (2.2\%), Hindu (1.5\%), atheist (1.4\%), or Buddhist (1.4\%). Of the partner subsample, 55.2\% reported religion or religious faith as very, extremely, or most important in their lives; $32.6 \%$ reported it as somewhat important, and $12.2 \%$ reported it as not at all important. Almost half were affiliated with a religious congregation (47.4\%). 
I conducted comparisons between the primary participants who were dropped from analysis ( $n=1989)$ and the respondent and partner subsamples ( $n$ 's $=621)$ using a series of ANOVA and Chi-square tests. Although there were no statistical differences between the dropped sample and the respondent subsample on religious affiliation, given our focus on cohabiting, partnered couples, the respondent subsample had a higher proportion of married couples $(F=737.89, p<.00)$ and, on average, earned more household income $(F=130.08, p<.00)$, was older $(F=46.9, p<.00)$, was more educated $(F=42.87, p<.00)$, and was less ethnically diverse than those who were dropped. For example, $67.1 \%$ of the respondent subsample was Caucasian, whereas $44 \%$ of the dropped sample was Caucasian $\left(\chi^{2}(1)=101.5, p<.00\right)$. Just over nine percent $(9.2 \%)$ of the respondent subsample was African American, compared to $24.4 \%$ of the dropped sample $\left(\chi^{2}(1)=66.8, p<.00\right)$. Just under $14 \%(13.8 \%)$ of the respondent subsample was Hispanic, compared to $23.6 \%$ of the dropped sample $\left(\chi^{2}(1)=26.8, p<.00\right)$. There was no significant difference in the proportion of Asian Americans in the respondent subsample $(9.3 \%)$ compared to the dropped sample $\left(7.2 \% ; \chi^{2}(1)=2.9, n s\right)$, or in the proportion of Native Americans (.5\% respondent and .8\% dropped; $\left.\chi^{2}(1)=.5, n s\right)$. These differences were expected, as more Caucasians than minorities are married (U.S. Census Bureau 2010, Table 57), and partnered people report higher household income (U.S. Census Bureau, 2010, Table 683), are better educated, and are older than their single counterparts (Waite, 1995).

The partner subsample was not significantly different from the dropped sample in terms of education (median level of educational attainment for both was high school diploma or equivalent) or religious affiliation. 


\section{Measures}

The following section details the measures used to assess the variables. I included in the analysis only those items that were asked of both respondents and their partners.

\section{Independent variables.}

Religious behaviors. Frequency of attendance at worship services not including weddings or funerals was assessed using a Likert-type scale, anchored with $1=$ never and $8=$ three or more times $a$ week (respondents: $M=3.38, S D=2.28$; partners: $M=3.81$, $S D=2.23$ ). Frequency of prayer (not including during worship services or before meals) was assessed on a scale anchored with $1=$ never and $9=$ three or more times a day (respondents: $M=4.68, S D=2.69$; partners: $M=4.92, S D=2.67$ ). Frequency of reading religious texts in the past year was assessed using a Likert-type scale, with $1=$ once and $8=$ once or more a day (respondents: $M=3.83, S D=2.10$; partners: $M=3.08$, $S D=2.34)$.

Biblical literalism. Biblical literalism has been defined as the extent to which individuals believe in the inerrancy of their religious texts (Read \& Eagle, 2009), and we used three items to assess this. The first two items assessed the extent to which respondents agreed $(1=$ strongly disagree to $5=$ strongly agree $)$ that there are errors in their religious text regarding moral, spiritual, or religious matters, and that there are errors in their religious text regarding science and history. The partner responses to these same items were coded $1=$ yes, $2=$ no, $3=$ don't know, or $4=$ no religion. To put respondent and partner responses on the same scale, we followed Read and Eagle's recoding procedure. All responses were recoded so that strongly disagree (for respondent data) or no (for partner data $)=1$. All other responses were coded as 0 . The 
third item asked whether respondents' religious text was fully inspired by God (1), partly inspired by God (2), or not at all inspired by God (3). Partner responses to the item "Is your religious text fully inspired by God?" were coded as $1=$ yes, $2=$ no, $3=$ don't know, and $4=$ no religion; all responses were recoded such that $1=y e s$ or fully inspired, and 0 $=$ all other responses. Read and Eagle used a fourth item, "I believe that the world was created in six, 24-hour days," but because this was not asked of partners, we did not include it in this analysis. Items were summed to create a composite variable, yielding possible scores ranging from 0 to 3 (respondents: $M=1.38, S D=1.2$; partners: $M=$ $1.68, S D=1.2)$. Cronbach's alpha was calculated for both respondents $(.81)$ and partners (.78).

Religious salience. Defined as the "perceived importance ascribed by individuals to their religious values and experiences” (Mason \& Spoth, 2010, p. 684), religious salience was assessed with two items: "How important is religion or religious faith to you personally?" and "How important is God or spirituality in your life?" Both items were on a 5-point Likert scale, with $1=$ not at all to $5=$ most important aspect in life.

Respondents' reported mean scores were $2.96(S D=1.21)$ and $3.27(S D=1.19)$ for the importance of religion and of spirituality, respectively. Partners' reported mean scores were $2.88(S D=1.23)$ and $3.20(S D=1.27)$, respectively.

\section{Dependent variable.}

Relationship satisfaction. Nine items were used to assess relationship satisfaction for both respondents and partners. Five items asked about the frequency of behaviors: How frequently does partner express affection or love, give compliments for the work done around the house or for parenting, performed small acts of kindness, 
insulted or criticized, or hit or slapped. These items were on a 6-point Likert-scale, anchored by $1=$ rarely and $6=$ once a day or more. (Respondent data originally included response options $6=$ once $a$ day and $7=$ more than once a day; these were combined to match the partner response scale). The remaining four items asked about satisfaction with various aspects of the relationship, including sex, process of decisionmaking, the love and affection received from partner, and the relationship as a whole. Responses ranged from $1=$ completely dissatisfied/unhappy to $7=$ completely satisfied/happy.

The item assessing frequency of being hit or slapped by one's partner was skewed, with over $90 \%$ reporting it never or rarely happened, so it was dropped from further analysis. An exploratory factor analysis with varimax rotation of the remaining eight items was conducted on the respondent data, producing two underlying factors. The first factor included behavioral items (e.g., "How frequently does your partner express love and affection?"; "How frequently does partner perform acts of kindness"). Item loadings ranged from .73 to .85 . The second factor extracted included evaluative items (e.g., "How satisfied are you with the process of decision-making in the relationship?"), with item loadings ranging from .79 to .83. The item "How frequently does partner criticize or insult" did not load satisfactorily onto either factor, and thus it was dropped from further analysis. The two-factor model was confirmed with confirmatory factor analysis using the partner data. All path loadings were significant and root mean standard error of approximation (RMSEA) indicated an acceptable fit (.07). 
Behavioral and evaluative subscales were created for respondents and partners, and Cronbach's alpha was calculated for each: (respondent behavior items $=.74$; respondent evaluative items $=.77$; partner behavior items $=.75$; partner evaluative items $=.75$ ). These subscales were used as the indicators in the latent relationship quality variable.

\section{Mediator variables.}

Joint religious activities. Defined as religious or spiritual behaviors experienced as a couple (Mahoney et al., 1999), joint religious activities were assessed with two items: "How often would you say you and your spouse/partner pray together, not including before meals and at religious services?" and "How often would you say you and your spouse/partner talk or read about religion, God, or spirituality together?" Both items were on a 6-point Likert-type scale, with $1=$ never and $6=$ once or more a day. Respondents' mean scores were $2.27(S D=1.68)$ and 2.93( $S D=1.61)$ for joint prayer and joint discussion, respectively, and partners' scores were $M=2.18(S D=1.6)$ and $M$ $=2.83(S D=1.61)$, respectively.

Social support. Participants were asked a series of questions about their social networks. First, participants identified the number of people living outside their home to whom they feel close. Reponses ranged from none to 20 or more. Those reporting none $(n=14)$ were not asked any further questions about social networks. Participants were asked specific questions about up to four people to whom they feel the closest.

Respondents who were affiliated with a congregation were asked to identify two more people specifically from their congregation; because this was not asked of partners, we did not include these social contacts in this analysis. 
For each social contact, participants were asked to identify those with whom they interacted once a week or more $(1=y e s, 0=n o$; respondents: $M=1.68, S D=1.37$; partners: $M=2.20, S D=1.43$ ), which social contact(s) volunteered their time to help them (respondents: $M=2.8, S D=1.43$; partners: $M=3.43, S D=.996$ ), and which gave money or a loan (respondents: $M=.73, S D=1.0$; partners: $M=.98, S D=1.25$ ). Scores for each item ranged from zero to four, indicating how many social contacts provided a particular type of support (i.e., interacted weekly or more, volunteered their time, or gave money). Scores were calculated for both respondents and partners and will be used as indicators to create a latent dyadic social support variable.

\section{Control variables.}

Religious affiliation. Both respondents and partners were asked their religious tradition ("Which of the following do you consider yourself?"). As a follow-up question, non-Catholic Christians were asked which denomination best described their religious faith or spirituality: Pentecostal (9\% of the respondent sample; 5.5\% of the partner sample), Charismatic (3.2\%; $2.7 \%)$, Fundamentalist $(4.3 \%, 2.4 \%)$, Evangelical (11.1\%, 10.9\%), Mainline Protestant (9.1\%, 10.6\%), Liberal Protestant (8.5 \%, 5.8\%), don't know (7.2\%, $8.5 \%)$, just Christian $(41 \%, 45 \%)$, or other $(2.3 \%, 7.9 \%)$. Responses were recoded onto a single variable and compared with their partners' responses. If partners matched in faith tradition and, for Protestants, in denomination, they were coded as $1=$ same faith (62.2\%). If partners' responses were different, it was coded as $0=$ different faith.

Education. All participants reported their highest level of education achieved. Scores ranged from $1=$ less than a high school diploma to $9=$ professional degree . 


\section{Plan of Analysis}

\section{Measurement of Religious Similarity}

The measurement of religious similarity was to be calculated using a profile similarity index score (Luo \& Klohnen, 2005). This is a couple-centered approach that uses within-in couple similarity as the basic unit of analysis. Although absolute difference scores and variable-centered approaches remain popular in the literature to capture similarity, they each have limitations that make them unfit for this study. Absolute difference scores are calculated by subtracting one partner's composite score from the other partner's, then calculating the absolute value of the difference. The resulting score ranges from zero (indicating partners have the same level of a particular attribute) to some positive number (indicating partners have different levels of the attribute). By using a composite score in the calculations, this approach cannot account for partners' actual similarity or dissimilarity across items.

The variable-centered approach (VCA) is one in which a correlation is calculated between partners' scores on a particular characteristic (e.g., extraversion). Negative correlations indicate that the sample as a whole is dissimilar, and positive correlations indicate similarity. This approach is limited. First, the VCA indicates the similarity of the sample, not the similarity of each couple; thus, it is difficult to use the VCA to predict relationship outcomes for couples. Second, it can be used only for a single characteristic; “it cannot provide any information on how similar partners are on more global, overarching individual domains" (Luo \& Klohnen, 2005, p. 304), such as religiosity.

Profile similarity index scores, by contrast, were to be calculated for every couple by correlating each partner's responses across all items for a particular domain (Q- 
correlation). The correlation scores range from a negative number (indicating partners are dissimilar, or that their pattern of responses across items was opposite) to a positive number (indicating similarity). A score of zero indicates that partners are neither similar nor dissimilar. Profile similarity index scores have been found to be stronger and more consistent predictors of relationship quality (Luo \& Klohnen, 2005) and relationship satisfaction (Gaunt, 2006) than absolute difference scores. Because this approach retains information of individual items, has the couple as the unit of analysis, provides an indicator of similarity for an overarching domain, and can be easily related to other variables, it was deemed appropriate to use in the analysis.

To calculate the index score, partners' data will be arranged in long form, i.e., each partner will be treated as a variable and their scores on all religiosity items will be listed as values under the variable. Second, a Q-correlation will be calculated for each couple using SPSS 20.0. This correlation will indicate religious similarity.

\section{Tests of Mediation Models}

Structural equation modeling in AMOS 20.0 was proposed to first test the direct relationship between the similarity profile index and relationship quality. Second, the proposed mediators of this relationship — joint religious activities and social supportwere tested in separate models using the Sobel test. The Sobel test indicates whether the effect of the independent variable (i.e., religious similarity) on the dependent variable (i.e., relationship quality) is significantly reduced when a mediator variable is present (Sobel, 1986). 


\section{Results}

Tables 1 and 2 present the descriptive statistics and correlations for the variables used in the analysis. The profile similarity index score for religious similarity was not able to be calculated due to the presence of the three binary items in the biblical literalism scale. Despite wide variability in responses to each item, binary items cannot be combined with continuous items to calculate a Q-correlation. As an initial alternative, a latent religious similarity score was created, with the intraclass correlations of respondent's and partner's scores of biblical literalism, religious behaviors, and religious salience as the three indicators. When using this latent variable, both the joint religious activities and the social support mediation models were unidentified. Despite attempts to make the models workable (e.g., correlating error terms where appropriate), they were chronically unidentified. It was determined that the latent religious similarity variable was not feasible, likely due to either issues of multicollinearity among the indicators or compressed variance of the indicator variables.

To address the similarity measurement issue, the intraclass correlations of biblical literalism, religious behaviors, and religious salience were averaged to create an indicator variable for average religious similarity. Intraclass correlations range from -1 , indicating perfect dissimilarity in partners' scores, to 1, indicating perfect similarity. This sample's scores ranged from -.91 to 1 , with a mean score of $.04(S D=.4)$, indicating chance similarity within couples. This religious similarity indicator was used for all subsequent models. To test the first hypothesis that religious similarity is significantly associated with relationship quality, I used religious similarity as the exogenous variable and latent relationship quality as the endogenous variable. Measures of fit indicate that the model 
fit the data well, as the Comparative Fit Index coefficient was close to $1.00(\mathrm{CFI}=.99)$. This coefficient has a maximum value of 1.00 , and higher values indicate a better fit of the model to the data. The RMSEA coefficient was low at .03. Low values are desirable, with values below .05 indicating a good fit (Bryne, 2001). Despite these goodness-of-fit statistics, religious similarity was not significantly associated with relationship quality (see Table 3); thus, no support was found for the first hypothesis.

Because some argue that a direct causal path between two variables is not necessary for a mediation effect to occur (e.g., Hayes, 2006), tests for mediation were conducted. Model 2 tested the second hypothesis that joint religious activities (as measured by frequency of joint prayer and joint religious discussion) would mediate the relationship between religious similarity and relationship quality. Where appropriate, error terms were allowed to correlate across partners; this correlation represents the latent nonindependence between partners (Kenny, Kashy, \& Cook, 2006). Only those correlations of errors that were significant were retained in the final model (Kenny et al.). Control variables of respondent and partner education were not significantly associated with relationship quality in this or any subsequent models; thus, they were removed from the analysis.

The paths between religious similarity and relationship quality and between religious similarity and joint religious activity were not significant (see Table 4), providing no support for the second hypothesis. However, the path between joint religious activity and relationship quality was significant. Findings from this model indicate that higher joint religious activity scores are associated with higher relationship quality scores. 
The third hypothesis, that social support will mediate the relationship between religious similarity and relationship quality, was tested in Model 3. Social support was hypothesized to be a latent variable with six indicators (i.e., both respondents' and partners' reports of how many social contacts have provided monetary assistance, volunteered their time, and had weekly or more frequent interaction). The fit of this model to the data was marginal, as indicated by a CFI below .90 , and the factor loadings for four of the six social support indicators were below the suggested cutoff score of .4 (Byrne, 2001; see Table 5). Therefore, alternative models were explored.

In the modified model, a more parsimonious, three-indicator latent social support variable was hypothesized to mediate the relationship between religious similarity and relationship quality. These indicators were calculated by averaging partners' and respondents' scores for each item (i.e., money, volunteer, frequency of contact), yielding the couple's average number of social contacts who provided monetary assistance, who volunteered their time to help, and who had weekly or more frequent interaction. The overall model fit improved with this modified model $\left(\chi^{2}\right.$ diff $\left.=97.71, p<.001\right)$. This significant improvement was anticipated, as the chi-square fit statistic is sensitive to more parsimonious models (Byrne, 2001). Because the other fit statistics (i.e., RMSEA, CFI)—which are less sensitive to model complexity—also improved, I deemed this modified model superior to the original hypothesized model. Neither the path between religious similarity and relationship quality nor the path between religious similarity and social support were significant (see Table 6). The path between social support and relationship quality was significant, and results indicate that greater social support was 
associated with higher relationship quality. These results do not support the hypothesized mediation effect for social support.

\section{Actual Versus Perceived Similarity}

For all the mediator models tested, religious similarity was not significantly related to the mediator variables, nor was it related to the relationship quality outcome variable. One possibility for this is the measurement of similarity used in this study. This study addressed actual similarity, as measured by intraclass correlations between partners' reports, but some argue that perceived similarity might be a more accurate and salient concept for partners (Selfhout, Denissen, Branje, \& Meeus, 2009). Because of this, a perceived religious similarity variable was created. All study participants were asked to rate how important religion is to them, as well as to rate how important they believe religion is to their partners. Items were on a 5-point Likert scale, with $1=$ not at all to $5=$ most important aspect in life (importance of religion to self for respondents: $M$ $=2.96, S D=1.21$, and for partners: $M=4.24, S D=3.59$. Perceived importance of religion to partner for respondents: $M=3.02, S D=1.19$, and for partners: $M=2.79, S D=$ 1.21). Responses to the item about one's partner were subtracted from the responses about oneself for each participant, yielding a range of scores from -4 to 4 for respondents' perceived religious similarity and from -3 to 4 for partners'. Positive scores indicate that participants perceived that religiosity was more important to them than it was to their partners; negative scores indicated that participants perceived that religion was more important to their partner than it was to them. A score of 0 indicated that participants perceived they and their partners were similar. 
Because this analysis was not concerned with individual differences (i.e., who is higher in religiosity than whom), the absolute difference was calculated, which indicated the magnitude of the perceived difference present within couples (a score of 4 indicates the largest perceived difference, and a score of 0 indicated no perceived difference). Scores were then reverse coded such that higher scores indicated greater perceptions of similarity. Mean scores for perceived religious similarity variables were $2.7(S D=1.0)$ and $3.4(S D=.80)$ for respondents and partners, respectively, indicating that on average respondents perceived themselves to be relatively similar to their partner, and vice versa. Compared to the average intraclass correlation measuring actual similarity, perceived similarity indicated much higher similarity.

Perceived religious similarity was then used as the independent variable (replacing actual similarity) in additional tests of the mediation models. Four models are presented here: respondents' perceptions of religious similarity with the joint religious activities mediator (see Table 7), partners' perceptions of religious similarity with the joint religious activities mediator (see Table 8), respondents' perceptions of religious similarity with the social support mediator (see Table 9), and partners' perceptions of religious similarity with the social support mediator (see Table 10).

Partners' perceived similarity was associated with relationship outcome indicators, specifically, with the evaluative dimensions for partners $(r=.09, p<.05)$ and for respondents $(r=.09, p<.05)$. Respondents' perceived religious similarity, however, was not correlated with relationship quality indicators. In the models with respondents' perceptions of similarity, similarity was unrelated to joint religious activities (Table 7), social support (Table 9), and relationship quality. The mediators were significantly 
related to relationship quality, as in the models above. These results, therefore, do not provide evidence of mediation, as theory suggests that the independent variable must be related to at least the mediator variables for mediation to occur (Baron \& Kenny, 1986).

In the model testing joint religious activities as a mediator for the relationship between partners' perception of similarity and relationship quality, similarity was significantly related to joint religious activities, but unrelated to relationship quality. Joint religious activities, in turn, were significantly associated with relationship quality. A Sobel test was performed to determine the magnitude of mediation. A Sobel test analyzes whether the indirect effect of the independent variable (i.e., partners' perceptions of religious similarity) on the dependent variable (i.e., relationship quality) through the mediator variable (i.e., joint religious activities) is significantly different from zero using the following equation: $a * b / \sqrt{ }\left(b^{2} * s a^{2}+a^{2} * s b^{2}\right)$, where $a$ is the regression coefficient from independent variable to the mediator, $b$ is the regression coefficient from the mediator to the dependent variable, $s a$ is the error of $a$, and $s b$ is the error of $b$ (Sobel, 1982). Sobel tests are best conducted in cases in which the sample size exceeds 400; it is appropriate in this analysis because the sample size is well beyond that (Baron \& Kenny, 1986).

The Sobel test indicated that a significant mediation effect was present $\left(z^{\prime}=2.37\right.$, $p=.02$ ), such that the association between perceived religious similarity and relationship quality was fully mediated by joint religious activities. It appears that perceiving religious similarity with one's partner was related to sharing more religious activities, which in turn was positively associated with relationship quality. 
In the model testing social support as mediating partners' perceptions of religious similarity and relationship quality, similarity was significantly associated with relationship quality, but not with social support (Table 10). Social support was significantly associated with relationship quality. These findings are contrary to the hypothesis and do not support mediation.

\section{Discussion}

Religious beliefs influence the way individuals organize their lives and make decisions about their families and relationships. According to the relational spirituality model (Mahoney, 2010), religion may influence couples' relationships through joint religious activities and social support. The current study tested the association between partners' religious similarity and relationship quality, and whether joint religious activities and social support mediated these associations.

The original hypotheses that religious similarity would be significantly associated with relationship quality and that this association would be mediated by joint religious activities and social support were not supported. Religious similarity, as measured with intra-class correlations among key indicators of religious belief and behavior, was neither significantly related to relationship quality nor to the mediators of joint religious activities and social support. Thus, I found no support for the relational spirituality model when using actual similarity between partners in this study. One possibility for this lack of support was that similarity was initially measured as actual, versus perceived, similarity. Perceived similarity may be more influential to relational outcomes than actual similarity. Those who perceived similarity with their partners may have their worldview and life decisions validated, feel understood, have more predictable (and 
therefore more enjoyable) interactions, and increased attraction to that person (Berg \& Clark, 1986). The opposite also might be true, that attraction leads to perceptions of similarity. Morry (2005) theorizes that because of a cultural belief that similarity is good, couples might create illusions of similarity to protect their choice of partner, their selfesteem, and, ultimately, their relationship satisfaction.

Including respondents' and partners' perceptions of religious similarity in the analysis produced a slightly different pattern of findings. Unlike actual similarity, perceived religious similarity significantly correlated with partners' and respondents' evaluative aspects of relationship quality (for partners' perceptions). This finding aligns with theory and previous research suggesting that perceptions of similarities are stronger correlates to relational outcomes than are actual similarities (Selfhout et al., 2009).

Of the hypothesized mediated models using perceived similarity, mediation was supported only when using partners ' perceptions of religious similarity with joint religious activities as the mediator. This is likely because partners perceived greater religious similarity in their relationships than did respondents. This finding provides empirical evidence for the relational spirituality framework, which theorizes that religion influences relationships through engagement in joint religious activities. Further, religious similarity may make it easier for couples to share religious beliefs and activities. Having a similar set of religious beliefs and practices may facilitate sharing these beliefs and practices with one's partner through discussions, prayer, or other behavior. Sharing these activities, having similar religious experiences, and responding to the world in a similar fashion is validating for each partner, provides reciprocal emotional responses, 
and opens up avenues for intimacy, thus benefiting perceptions of overall relationship quality and stability (Anderson, Keltner, \& John, 2003).

Contrary to the hypotheses, there was no evidence of mediation for models using actual religious similarity, for social support mediation models with partners' perceived religious similarity, or for models with respondents' perceived religious similarity. The contradictory findings might suggest a need to modify hypotheses to include a moderation effect, rather than a mediated one. Although the relational spirituality framework suggests mediation - that religion would affect relationships through social support and joint religious activities - this was only supported in one of the seven models tested. A moderation effect might, for example, suggest that joint religious activities would influence relationship quality, but only for couples who are both highly religious. This is a promising avenue for future research to explore.

It might also be that a third, unmeasured variable is confounding the results. Social network overlap, for example, may be used to explain the unexpected result that neither actual nor perceived religious similarity is related to social support. Perhaps similarity in social network, rather than religiousness, is more closely linked to social support and, therefore, relationship quality. There is some evidence to suggest that social support might enhance relationship quality when partners' individual social networks are overlapping or have similar worldviews (Kearns \& Leonard, 2004). When the social networks are markedly different, social contacts may provide partners contradictory advice - or advice subverting and invalidating the decisions the couple have made (Kalmijn, 1998). In this situation, social support may be high, but relationship outcomes may be adversely affected. The present study does not account for the content of the 
support (except being offered a loan), nor does it account for the overlap of partners' social networks. This might be a fruitful direction for future research.

A second potential confounding variable is length of relationship. Couples who have been together longer are thought to increase their similarity over time; this is a process called convergence (Gonzaga, Carter, \& Buckwalter, 2010). Sharing key emotional experiences and consciously focusing on compatibilities appear to reduce dissimilarities within couples. Some evidence suggests that interests (including interest in religious community, religious faith, and church involvement) become more similar over time, and the greater the convergence, the more satisfied the marriage (Gonzaga et al., 2010). Length of relationship was not assessed in the PALS study, but it could be that this data were skewed with couples relatively early in their relationship, so similarity was not as great, or as salient, as it may be in other samples.

Secularization, the declining importance of religion for individuals, may also be used to explain these results. In the last half century, fewer American adults are formally affiliated with a religious congregation, and those who are report less frequent attendance (see Sherkat, 2004). An important element in secularization is religious beliefs and practices becoming more private and internal, rather than public and external. This has resulted in less bright boundaries between religious groups, less societal or institutional pressure to identify with and conform to religious norms, increasing rates of interfaith relationships, and, for some, a decrease of importance of religion. It could be that religious similarity just is not as salient as other factors in influencing relationship quality. Indeed, Myers (2006) found that gender and work issues have become more 
salient predictors of marital quality than religion in the past generation. Future work drawing on the PALS dataset should explore these possibilities.

Further, this analysis focused on religiousness of participants, rather than spirituality. A growing segment of the population is identifying as spiritual, but not religious (Marler \& Hadaway, 2002; Shahabi et al., 2002; Zinnbauer et al., 1997). Perhaps the narrow focus of the analysis and the religiosity questions in the survey were simply not relevant to a significant portion of the sample; including questions about spirituality (e.g., direct experiences of the deity or higher power) may have been more relevant to the sample and therefore may have influenced results more than religiousness only.

A final consideration to explain the unexpected results could be that religious complementarity, rather than similarity, is important for couples in influencing their relationship quality. The concept of complementarity suggests that moderate differences between partners - rather than perfect matching or extreme differences - may benefit the relationship. Pilkington, Tesser, and Stephens (1991) contend that complementarity is an aspect of similarity; individuals may narrow a field of eligible partners based on similar values, worldviews, and personalities, and from this homogenous group choose a partner who has complementary differences. Doing so may preserve one's self-concept over time (Pilkington et al., 1991), provide each partner a functional niche within the relationship, thereby reducing conflict and improving stability (White \& Klein, 2002), and lead to flexibility in a relationship (Horlacher, Miller, \& Holman, nd).

Assessing religious complementarity (i.e., partners having a one-unit difference on response scales) may be more appropriate in this analysis than religious similarity 
(i.e., matching between partners' reports), as it could be that couples function well when both have a fundamental agreement in values and religious views, but when religious salience is slightly more important for one partner than the other. Salience serves as a moderator in studies of complementarity, whereas in this analysis, it was just one dimension by which I assessed similarity. Measuring complementarity also requires using both partners' reports, rather than one partner's perceptions, as “even when differences were observed which fit the expected complementary pattern (dominant/submissive), participants perceived themselves as similar in those areas" (Dryer \& Horowitz, 1997, as cited in Horlacher et al., $n d$, p. 7).

Although there was little evidence for the proposed mediation models, several main effects worth noting emerged. Partners' perceived religious similarity was significantly positively associated with joint religious activities. This indicates that partners who perceived greater religious similarity also report more frequent prayer and discussion about religious issues with their partner. Perhaps the similarity one perceives with a partner enables them to share religious or spiritual beliefs, ideas, and feelings more frequently. Reiter and Gee (2008) found that religious similarity led to more discussions about religion. It could also be that praying together, discussing religious issues, and reading religious texts as a couple alters partners' perceptions of their similarity. In other words, perhaps more frequent joint religious activities leads to partners perceiving greater religious similarity.

In all the tested models, joint religious activities were significantly and positively associated with relationship quality. It appears that couples who more frequently pray and read religious texts together, discuss religious issues, and engage with each other 
about their religious beliefs, have perceptions of greater relationship quality. Because, for many, religion and religious beliefs reflect a deep and personal aspect of themselves, the ability to share this with a partner may indicate a trusting, bonded, and respectful relationship. Indeed, Williams and Lawler (2000) and Mahoney and colleagues (1999) found an association between joint religious activities and greater intimacy and more constructive communication strategies in relationships. Further, greater joint religious activities theoretically renders the relationship a spiritual place - that is, a place to directly experience God or the divine. This may lead to partners' greater protection of and investment in the relationship, which in turn benefits relationship quality.

Social support was also significantly positively associated with relationship quality in all tested models. Those couples who reported high levels of support in terms of frequent social interaction, being offered money, or having friends who volunteer their time to help were also more likely to report high levels of relationship quality. These findings lend support to previous research and theory (Krause, 2008) that greater social support, be it emotional or instrumental in nature, may mitigate stress for couples and improve physical and mental health of individuals (Cohen, 2004), thereby enhancing relationship quality. Furthermore, because social support was measured by averaging individual partner's social support scores, these findings suggest that both receiving support directly from one's own social network and having a partner who receives support from his or her social network benefits the relationship itself. In other words, individual support has dyadic consequences. This supports previous research by Julian and Markman (1992) which suggested that one partner's social support benefited the relationship as a whole. 


\section{Implications}

There are theoretical, research, and application implications of the current study.

First, this is the first study I have found to test the theorized mediating mechanisms of the relational spiritual framework. While this single study does not provide enough evidence to justify validating or invalidating the framework, it is a starting place for future research. Evaluating and establishing the validity of this mid-range theory is important in the field of religion and relationships, as it can serve to coherently thread together multiple findings and standardize measures and operationalization of constructs. Without this standardization (which has been problematic in the field; for a review, see Hill \& Hood, 1999), findings cannot be compared or aggregated to create a body of knowledge. In sum, starting to validate and evaluate the relationship spirituality framework is beneficial to the field and to future research.

Second, this study replicates and/or extends previous research. This study replicated the significant positive relationship between joint religious activities and relationship quality, and it extended the literature to include joint religious activities as a mediator between religious similarity and relationship quality. The study replicated the finding that social support is significantly positively related to relationship quality, and it added to the scant evidence that one partners' social support benefits the couple as a whole. Additionally, the current analysis poses many more questions for future study, such as the difference between actual similarity, globally assessed perceived similarity, and specifically assessed perceived similarity, the influence of third variables (e.g., social network overlap, length of relationship), longitudinal effects (e.g., secularization, convergence), moderation effects (e.g., religious-only sample), and the effects of a 
nuanced religious similarity measure versus a single indicator. In other words, there is more to know.

Third, this study has clear implications for application, particularly for premarital or marital counselors or family life educators. Establishing joint religious activities and being active in a social network is clearly related to relationship quality, and it can be extrapolated that couples benefit by being deliberate at engaging in joint religious activities, despite any religious differences between partners.

\section{Limitations and Strengths of the Current Analysis}

The limitations of this study are primarily related to measurement. Because this was a secondary data set, the measurement of variables was limited to questions asked of the PALS participants. It is possible that the items used to measure the variables examined here were not sensitive to important aspects of the proposed constructs, or could not capture the entirety of a construct as other items might be that were not available in the data. For example, only two items were asked of each respondent and partner to assess joint religious activities: the frequency of joint prayer and of discussing religious issues or reading religious texts. In a study by Mahoney and colleagues (1999), joint religious activities were assessed using a 13-item scale. Items included discussing God's will in the relationship and celebrating religious rituals and holidays. More items and response options may have captured more variability related to religious similarity or relationship quality that was not available for this particular construct.

The measurement of religious similarity was also limited. Questions of Biblical literalism for partners were on a binary scale, rendering a profile index score incalculable. Furthermore, additional questions could have improved the sensitivity of the measure, 
including religious commitment, other religious behaviors (e.g., attending groups, talking with friends about religious issues, religious identity) that could have provided information not only about one's level of religiousness, but also about one's integration in the religious community. These additional items might have more strongly correlated with joint religious activities, social support, and relationship quality.

Furthermore, perceived religious similarity was assessed with a single indicator: the difference between the participant's own importance of religion and the participant's perception of partner's importance of religion. Other studies using perceived similarity use multiple items to create a composite score of perceived similarity (Gonzaga et al., 2010). A more sensitive measurement of perceived religious similarity may have detected a stronger relationship to relationship quality, social support, and joint religious activities.

The analysis was also limited to questions asked of both respondents and partners because of the dyadic nature of the hypotheses. Respondents were asked significantly more questions related to the constructs (including religious experiences, behaviors, and beliefs, and social support) and had a wider range of response options than partners. For example, respondents were asked five questions related to Biblical literalism and could answer on a five-point Likert scale, but partners were asked only three and were offered binary response options. This limited the range of the scale and, potentially, the findings.

Strengths include the dyadic nature of the analysis. Dyadic studies on the influence of religion on relationships, although becoming more common, are far from commonplace, and they can uncover new correlations or, as in this analysis, can challenge theory established with individually-focused research designs. Further, this 
analysis had a large sample size, which is rare in dyadic studies of religion. This allowed me the power to use sophisticated analysis (i.e., structural equation modeling) to simultaneously test several relationships that would not have been possible with fewer participants.

Second, the PALS data set is already expanding, with the second wave of data already having been collected. This will allow future studies to look at the effects of religion, religious similarity, social network, and religious activities on relationship quality over time. Theories of secularization and convergence, for example, can be tested explicitly to further the current study. A final strength of this analysis is that it directly tests an established theory. This allows the field to move forward, either with additional research designed to correct the limitations of the current analysis to verify its results, or with a modification of the theory. Either way, the knowledge of religious similarity and its influence on joint religious activities, social support, and relationship quality has increased.

\section{Conclusion}

Taken as a whole, the findings of this analysis further the literature of religion's influence on couples. Religion is connected to relationship quality primarily through couples' joint behavior - the actions taken and the experiences shared with partners motivated by religion. The present study extends previous literature on joint religious activities, and it replicates research on social support and relationship quality. The study also leaves more questions to be answered: Could the models be modified to include a moderation effect? Does the overlap of partners' social networks influence relationship quality or religious similarity? How do these associations change over time, and how do 
other variables (e.g., work and gender issues) influence these associations? The field is open for exploration. 


\section{References}

Anderson, C., Keltner, D., \& John, O. P. (2003). Emotional convergence between people over time. Journal of Personality and Social Psychology, 84, 1054-1068.

Baron, R. M., \& Kenny, D. A. (1986). The moderator-mediator variable distinction in social psychological research: Conceptual, strategic, and statistical considerations. Journal of Personality and Social Psychology, 51, 1173-1182.

Beach, S. R. H., Fincham, F. D., Hurt, T. R., McNair, L. M., \& Stanley, S. M. (2008). Prayer and marital intervention: A conceptual framework. Journal of Social and Clinical Psychology, 27, 641-669.

Berg, J. H., \& Clark, M. S. (1986). Differences in social exchange between intimate and other relationships: Gradually evolving or quickly apparent? In V. J. Derlega \& B. A. Winsted (Eds.), Friendship and social interaction (pp. 101-128). New York: Springer.

Booth, A., Johnson, D., Branaman, A., \& Sica, A. (1995). Belief and behavior: Does religion matter in today's marriage? Journal of Marriage and the Family, 57, 661671.

Butler, M. H., Gardner, B. C., \& Bird, M. H. (1998).Not just a time out: Change dynamics of prayer for religious couples in conflict situations. Family Process, 37, 451-475.

Butler, M. H., Stout, J. A., \& Gardner, B. C. (2002). Prayer as a conflict resolution ritual: Clinical implications of religious couples' report of relationship softening, healing perspective, and change responsibility. The American Journal of Family Therapy, 30, 19-37. 
Call, V. R. A., \& Heaton, T. B. (1997). Religious influence on marital stability. Journal for the Scientific Study of Religion, 36, 382-392.

Chinitz, J. G., \& Brown, R. A., (2001). Religious homogamy, marital conflict, and stability in same-faith and interfaith Jewish marriages. Journal for the Scientific Study of Religion, 40, 723-733.

Cohen, S. (2004). Social relationships and health. American Psychologist, 59, 676-684.

Curtis, K. T., \& Ellison, C. G. (2002). Religious heterogamy and marital conflict: Findings from the National Survey of Families and Households. Journal of Family Issues, 23, 551-576.

Dryer, D. C., \& Horowitz, L. M. (1997). When do opposites attract? Interpersonal complementarity versus similarity. Journal of Personality and Social Psychology, 72, 592-603.

Eliasson, A. H., Taylor, J., \& Lloyd, D. A. (2005). Subjective religiosity and depression in transition to adulthood. Journal for the Scientific Study of Religion, 34, 187199.

Ellison, C. G., Boardman, J. D., Williams, D. R., \& Jackson, J. A. (2001). Religious involvement, stress, and mental health: Findings from the 1995 Detroit Area Study. Social Forces, 80, 215-249.

Ellison, C. G., Burdette, A. M., \& Wilcox, W. B. (2010). The couple that prays together: Race and ethnicity, religion, and relationship quality among working-age adults. Journal of Marriage and Family, 72, 963-975). 
Ellison, C. G., \& George, L. K. (1994). Religious involvement, social ties, and social support in a southeastern community. Journal for the Scientific Study of Religion, $33,46-61$.

Gaunt, R. (2006). Couple similarity and marital satisfaction: Are similar spouses happier? Journal of Personality, 74, 1401-1420.

Gonzaga, G. C., Carter, S., \& Buckwalter, J. G. (2010). Assortative mating, convergence, and satisfaction in married couples. Personal Relationships, 17, 634-644.

Gruner, L. (1985). The correlation of private, religious devotional practices and marital adjustment. Journal of Comparative Family Studies, 16, 47-59.

Heaton, T. B. (1984). Religious homogamy and marital satisfaction reconsidered. Journal of Marriage and the Family, 46, 729-733.

Heaton, T. B., \& Pratt, D. L. (1990). The effects of religious homogamy on marital satisfaction and stability. Journal of Family Issues, 11, 191-207.

Hill, P. C., \& Hood, R. W. (1999). Measures of Religiosity. Birmingham, AL: Religious Education Press.

Horlacher, G. T., Miller, R. B., Holman, T. B. (nd). Theory and measurement of complementarity in intimate relationships. Paper presented at the National Conference of Family and Relationships.

Julien, D., \& Markman, H. J. (1992). Social support and social networks as determinants of individual marital outcomes. Journal of Social and Personal Relationships, 8, 251-268.

Kalmijn, M. (1998). Intermarriage and homogamy: Causes, patterns, trends. Annual Review of Sociology, 24, 395-421. 
Kaplan, J. (2004). Interfaith Families: Personal Stories of Jewish-Christian Intermarriage. Westport, CT: Praeger.

Karney, B. R., \& Bradbury, T. N. (1995). The longitudinal course of marital quality and stability: A review of theory, method, and research. Psychological Bulletin, 118, 3-34.

Kearns, J. N., \& Leonard, K. E. (2004). Social networks, structural interdependence, and marital quality over the transition to marriage: A prospective analysis. Journal of Family Psychology, 18, 383-395.

Klohnen, E. C., \& Mendelsohn, G. A. (1998). Partner selection for personality characteristics: A couple-centered approach. Personality and Social Psychology Bulletin, 24, 268-278.

Krause, N. M. (2002). A comprehensive strategy for developing closed-ended survey items for use in studies of older adults. Journal of Gerontology: Social Sciences, 57B, S263-S274.

Krause, N. M. (2008). Aging in the church: How social relationships affect health. Templeton Foundation Press: West Conshonhocken, PA.

Lehrer, E. L., \& Chiswick, C. U. (1993). Religion as a determinant of marital stability. Demography, 30, 385-404.

Luo, S., \& Klohnen, E. C. (2005). Assortative mating and marital quality in newlyweds: A couple-centered approach. Journal of Personality and Social Psychology, 88, 304-326.

Mahoney, A. (2010). Religion in families, 1999-2009: A relational spirituality framework. Journal of Marriage and Family, 72, 805-827. 
Mahoney, A., Pargament, K. I., Jewell, T., Swank, A. B., Scott, E., Emery, E., \& Rye, M. (1999). Marriage and the spiritual realm: The role of proximal and distal religious constructs in marital functioning. Journal of Family Psychology, 13, 321-338.

Mahoney, A., Pargament, K. I., Tarakeshwar, N., \& Swank, A. B. (2008). Religion in the home in the 1980s and 1990s: A meta-analytic review and conceptual analysis of links between religion, marriage, and parenting. Journal of Family Psychology, $15,559-596$.

Marler, P. L., \& Hadaway, C. K. (2002). "Being religious" or "being spiritual" in America: A zero-sum proposition? Journal for the Scientific Study of Religion, 41, 289-300.

Miller, R. S. (2008). Attending to temptation: The operation (and perils) of attention to alternatives in close relationships. In J. P. Forgas \& J. Fitness (Eds.), Social relationships: Cognitive, affective and motivational processes (pp. 321-337). New York: Psychology Press.

Morry, M. M. (2005). Relationship satisfaction as a predictor of similarity ratings: A test of the attraction-similarity hypothesis. Journal of Social and Personal Relationships, 22, 561-584.

Myers, S. M. (2006). Religious homogamy and marital quality: Historical and generational patterns, 1980-1997. Journal of Marriage and Family, 68, 292-304.

Pargament, K. I., \& Mahoney, A. (2002). Spirituality: Discovering and conserving the sacred. In C. R. Snyder (Ed.), Handbook of positive psychology (pp. 646-675). Washington, DC: American Psychological Association. 
The Pew Forum on Religion and Family Life (2010). Religion and Public Life Survey. Pew Research Center.

Reiter, M. J., \& Gee, C. B. (2008). Open communication and partner support in intercultural and interfaith romantic relationships: A relational maintenance approach. Journal of Social and Personal Relationships, 25, 539-559.

Sobel, M. E. (1982). Asymptotic intervals for indirect effects in structural equations models. In S. Leinhart (Ed.), Sociological Methodology (pp.290-312). San Francisco: Jossey-Bass.

Schramm, D. G., Marshall, J. P., Harris, V. W., \& Lee, T. R. (2012). Religiosity, homogamy, and marital adjustment: An examination of newlyweds in first marriages and remarriages. Journal of Family Issues, 33, 246-268.

Seidlitz, L., Abernethy, A. D., Duberstein, P. R., Evinger, J. S., Chang, T. H., \& Lewis, B. L. (2002). Development of the Spiritual Transcendence Index. Journal for the Scientific Study of Religion, 41, 439-453.

Shahabi, L., Powell, L. H., Musick, M. A., Pargament, K. I., Thoresen, C. E., Williams, D. Underwood, L., \& Ory, M. A. (2002). Correlates of self-perceptions of spirituality in American adults. Annals or Behavioral Medicine, 24, 59-68.

Selfhout, M., Denissen, J., Branje, S., \& Meeus, W. (2009). In the eye of the beholder: Perceived, actual, and peer-related similarity in personality, communication, and friendship intensity during the acquaintanceship process. Journal of Personality and Social Psychology, 96, 1152-1165.

Smith, C., \& Pearce, L. (2003). National Study of Youth and Religion, Wave 1. Lilly Endowment Fund. 
Sobel, M. E. (1986). Some new results on indirect effects and their standard errors in covariance structure. Sociological Methodology, 16, 159-186.

Sorenson, A. M., Grindstaff, C. F., \& Turner, R. J. (1995). Religious involvement among unmarried adolescent mothers: A source of emotional support? Sociology of Religion, 56, 71-81.

Strong, G., \& Aron, A. (2006).The effect of shared participation in novel and challenging activities on experienced relationship quality: Is it mediated by high positive affect? In K. D. Vohs \& E. J. Finkel (Eds.), Self and Relationships: Connecting Intrapersonal and Interpersonal Processes (pp.342-359). New York: Guilford.

Taylor, R. J. \& Chatters, L. M. (1988). Church members as a source of informal social support. Review of Religious Research, 30, 193-203.

Vaaler, M. L., Ellison, C. G., \& Powers, D. A. (2009). Religious influence on the risk of marital dissolution. Journal of Marriage and Family, 71, 917-934.

White, J.M., and Klein, D.M. (2002). Family theories: Understanding families. Thousand Oaks, CA: Sage Publications. 1-259.

Winter, J. A. (2002). Consistency importance of Jewish identity and one's own or one's and child's intermarriage. Review of Religious Research, 44, 38-57.

Zinnbauer, B. J., Pargament, K. I., Cole, B., Rye, M. S., Butter, E. M., Belavich, T. G., et al. (1997). Religion and spirituality: Unfuzzying the fuzzy. Journal for the Scientific Study of Religion, 36, 549-564. 
Table 1

Descriptive Statistics

\begin{tabular}{|c|c|c|c|c|c|}
\hline Item & $\mathrm{N}$ & Minimum & Maximum & Mean & $\begin{array}{l}\text { Standard } \\
\text { Deviation }\end{array}$ \\
\hline Similarity Average ICC & 621 & -0.91 & 1.00 & 0.04 & 0.40 \\
\hline $\mathrm{R}^{\mathrm{a}}$ Perception of Similarity & 576 & 0.00 & 4.00 & 2.67 & 1.03 \\
\hline $\mathrm{P}^{\mathrm{b}}$ Perception of Similarity & 606 & 0.00 & 4.00 & 3.42 & 0.81 \\
\hline R Contact & 621 & 1.00 & 5.00 & 2.68 & 1.37 \\
\hline P Contact & 621 & 1.00 & 5.00 & 3.20 & 1.43 \\
\hline R Volunteer & 620 & 1.00 & 5.00 & 3.82 & 1.43 \\
\hline P Volunteer & 470 & 1.00 & 5.00 & 4.44 & 1.00 \\
\hline R Money & 620 & 1.00 & 5.00 & 1.73 & 1.04 \\
\hline P Money & 476 & 1.00 & 5.00 & 1.98 & 1.25 \\
\hline Average Contact & 620 & 0.00 & 4.00 & 1.94 & 1.09 \\
\hline Average Volunteer & 469 & 0.00 & 4.00 & 3.17 & 0.87 \\
\hline Average Money & 475 & 0.00 & 4.00 & 0.85 & 0.98 \\
\hline R Talk Together & 610 & 1.00 & 6.00 & 2.93 & 1.57 \\
\hline P Talk Together & 601 & 1.00 & 6.00 & 2.83 & 1.61 \\
\hline R Pray Together & 611 & 1.00 & 6.00 & 2.27 & 1.67 \\
\hline P Pray Together & 601 & 1.00 & 6.00 & 2.18 & 1.60 \\
\hline $\begin{array}{l}\text { R Behavioral } \\
\text { Relationship Quality }\end{array}$ & 604 & 3.00 & 21.00 & 15.55 & 3.82 \\
\hline $\begin{array}{l}\text { P Behavioral } \\
\text { Relationship Quality }\end{array}$ & 598 & 3.00 & 18.00 & 14.33 & 3.38 \\
\hline $\begin{array}{l}\text { R Evaluative } \\
\text { Relationship Quality }\end{array}$ & 598 & 4.00 & 22.00 & 18.13 & 3.69 \\
\hline $\begin{array}{l}\text { P Evaluative } \\
\text { Relationship Quality }\end{array}$ & 586 & 4.00 & 22.00 & 18.39 & 3.21 \\
\hline $\begin{array}{l}\text { Denominational } \\
\text { Similarity }\end{array}$ & 621 & 0.00 & 1.00 & .62 & .49 \\
\hline
\end{tabular}


Table 2

Correlations among Similarity, Joint Religious Activities, Social Support, and Relationship Quality Variables

\begin{tabular}{|c|c|c|c|c|c|}
\hline Variables & 1 & 2 & 3 & 4 & 5 \\
\hline 1. Similarity $\mathrm{ICC}^{\mathrm{a}}$ & - & & & & \\
\hline 2. $\mathrm{R}^{\mathrm{b}}$ Perceptions of Similarity & -.05 & - & & & \\
\hline 3. $\mathrm{P}^{\mathrm{c}}$ Perceptions of Similarity & .01 & .06 & - & & \\
\hline 4. R Contact & .02 & $-.09 *$ & .02 & - & \\
\hline 5. P Contact & .01 & -.01 & .00 & $.21 * *$ & - \\
\hline 6. R Volunteer & -.03 & -.03 & -.05 & $.26 * *$ & .05 \\
\hline 7. $\mathrm{P}$ Volunteer & .05 & .08 & -.03 & $.10^{*}$ & $.21 * *$ \\
\hline 8. R Money & .00 & .05 & -.36 & $.10^{*}$ & $.11^{* *}$ \\
\hline 9. P Money & .07 & .01 & -.04 & $.13^{* *}$ & $.21 * *$ \\
\hline 10. Contact Average & .02 & -.07 & .01 & $.77 * *$ & $.79 * *$ \\
\hline 11. Volunteer Average & .00 & .03 & -.06 & $22 * *$ & $.14 * *$ \\
\hline 12. Money Average & .06 & .02 & -.01 & $.11 *$ & $.19 * *$ \\
\hline 13. R Talk Together & -.01 & -.01 & $.12 * *$ & $.09 * *$ & $.13 * *$ \\
\hline 14. P Talk Together & .04 & -.01 & .06 & $.12 * *$ & $.11 *$ \\
\hline 15. R Pray Together & -.01 & -.01 & $.13 * *$ & $.12 * *$ & .07 \\
\hline 16. P Pray Together & .00 & .01 & $.10^{*}$ & $.19 * *$ & $.14 * *$ \\
\hline 17. R Behavioral & .03 & .08 & .06 & .06 & .04 \\
\hline 18. P Behavioral & .07 & -.02 & .01 & $.12 * *$ & $.09 *$ \\
\hline 19. R Evaluative & -.02 & .03 & $.09 *$ & $.17 * *$ & .07 \\
\hline 20. P Evaluative & .07 & -.02 & $.09 *$ & $.09 *$ & .07 \\
\hline 21. Denominational Similarity & .00 & -.04 & $.10 *$ & $.11 * *$ & $.11 * *$ \\
\hline
\end{tabular}


Table 2

Continued

\begin{tabular}{|c|c|c|c|c|c|}
\hline Variables & 6 & 7 & 8 & 9 & 10 \\
\hline 6. R Volunteer & - & & & & \\
\hline 7. P Volunteer & .03 & - & & & \\
\hline 8. R Money & $.21 * *$ & $.14 * *$ & - & & \\
\hline 9. P Money & .03 & $.18 * *$ & $.47 * *$ & - & \\
\hline 10. Contact Average & $.20 * *$ & $.20 * *$ & $.13 * *$ & $.22 * *$ & - \\
\hline 11. Volunteer Average & $.82 * *$ & $.59 * *$ & $.24 * *$ & $.12 * *$ & $.23 * *$ \\
\hline 12. Money Average & $.12 * *$ & $.19 * *$ & $.82 * *$ & $.89 * *$ & $.19 * *$ \\
\hline 13. R Talk Together & .03 & $.14 * *$ & .00 & .02 & $.89 * *$ \\
\hline 14. P Talk Together & .01 & $.15^{* *}$ & $.08^{*}$ & $.10^{*}$ & $.14 * *$ \\
\hline 15. R Pray Together & .02 & $.10^{*}$ & .01 & .03 & $.13^{* *}$ \\
\hline 16. P Pray Together & .06 & $.10^{*}$ & -.01 & .03 & $.21 * *$ \\
\hline 17. R Behavioral & $.09 *$ & .03 & $.08^{*}$ & .06 & .06 \\
\hline 18. P Behavioral & $.10 *$ & $.11 *$ & $.08^{*}$ & .04 & $.13 * *$ \\
\hline 19. R Evaluative & .03 & -.02 & .02 & -.07 & $.15 * *$ \\
\hline 20. P Evaluative & .00 & .07 & -.02 & $.14 * *$ & $.14^{* *}$ \\
\hline 21. Denominational Similarity & .00 & .06 & $-.09 *$ & -.01 & $.14 * *$ \\
\hline
\end{tabular}


Table 2

Continued

\begin{tabular}{|c|c|c|c|c|c|}
\hline Variables & 11 & 12 & 13 & 14 & 15 \\
\hline 11. Volunteer Average & - & & & & \\
\hline 12. Money Average & $.23 * *$ & - & & & \\
\hline 13. R Talk Together & $.19 * *$ & $.20 * *$ & - & & \\
\hline 14. P Talk Together & .09 & .07 & $.65^{*}$ & - & \\
\hline 15. R Pray Together & .08 & .00 & $.69 * *$ & $.56^{* *}$ & - \\
\hline 16. P Pray Together & $.10 * *$ & .00 & $.51 * *$ & $.65^{* *}$ & $.63 * *$ \\
\hline 17. R Behavioral & .06 & .08 & $.28 * *$ & $.13 * *$ & $.25 * *$ \\
\hline 18. P Behavioral & .09 & .06 & $.25^{* *}$ & $.31 * *$ & $.22 *$ \\
\hline 19. R Evaluative & .00 & -.06 & $.20 * *$ & $.13 * *$ & $.22 * *$ \\
\hline 20. P Evaluative & .00 & .02 & $.23 * *$ & $.27 * *$ & $.20 * *$ \\
\hline 21. Denominational Similarity & .05 & $.26 * *$ & $.26 * *$ & $.29 * *$ & $.26^{* * *}$ \\
\hline
\end{tabular}


Table 2

Continued

\begin{tabular}{lcccccc}
\hline Variables & 16 & 17 & 18 & 19 & 20 & 21 \\
\hline 16. P Pray Together & - & & & & \\
17. R Behavioral & $.12^{* *}$ & - & & & \\
18. P Behavioral & $.29^{* *}$ & $.34^{* *}$ & - & & \\
19. R Evaluative & $.16^{* *}$ & $.44^{* *}$ & $.24 * *$ & - & \\
20. P Evaluative & $.24^{* *}$ & $.37^{* *}$ & $.51^{* *}$ & $.36^{* *}$ & - & \\
21. Denomination Similarity & $.27^{* *}$ & .00 & $.10^{*}$ & $.10^{*}$ & $.11^{* *}$ & - \\
\hline
\end{tabular}

${ }^{a}$ Similarity ICC $=$ Average of biblical literalism, religious salience, and religious behaviors intraclass correlations. ${ }^{\mathrm{b}} \mathrm{R}=$ Respondent responses. ${ }^{\mathrm{c}} \mathrm{P}=$ Partner responses. $* p<.05 . * * p<.01$. 
Table 3

Unstandardized Estimates, Standardized Estimates, and Significance Levels for Religious

Similarity and Relationship Quality (Standard Errors in Parentheses; $N=621$ )

\begin{tabular}{llll}
\hline Parameter Estimate & Unstandardized & Standardized & P
\end{tabular}

\begin{tabular}{|c|c|c|c|}
\hline \multicolumn{4}{|l|}{ Measurement Model Estimates } \\
\hline Relationship Quality $\rightarrow \mathrm{P}^{\mathrm{a}}$ Behavioral & 1.00 & .64 & .00 \\
\hline Relationship Quality $\rightarrow \mathrm{R}^{\mathrm{b}}$ Behavioral & $.85(.09)$ & .49 & .00 \\
\hline Relationship Quality $\rightarrow$ P Evaluative & $1.17(.12)$ & .79 & .00 \\
\hline Relationship Quality $\rightarrow$ R Evaluative & $.75(.09)$ & .44 & .00 \\
\hline Denominational Similarity $\rightarrow$ & $.62(.21)$ & .14 & .00 \\
\hline \multicolumn{4}{|l|}{ Relationship Quality } \\
\hline Error in P Behavioral & $6.77(.60)$ & & .00 \\
\hline Error in $\mathrm{R}$ Behavioral & $11.14(.75)$ & & .00 \\
\hline Error in P Evaluative & $3.80(.66)$ & & .00 \\
\hline Error in R Evaluative & $10.96(.71)$ & & .00 \\
\hline Covariance $\mathrm{R}$ Behavioral and $\mathrm{R}$ & $3.20(.56)$ & & .00 \\
\hline \multicolumn{4}{|l|}{ Evaluative } \\
\hline \multicolumn{4}{|l|}{ Structural Model Estimates } \\
\hline $\begin{array}{l}\text { Religious Similarity } \rightarrow \text { Relationship } \\
\text { Quality }\end{array}$ & $.40(.26)$ & .07 & .13 \\
\hline
\end{tabular}


Table 4

Unstandardized Estimates, Standardized Estimates, and Significance Levels for Joint

Religious Activities Mediation (Standard Errors in Parentheses; $N=621$ )

\begin{tabular}{|c|c|c|c|}
\hline Parameter Estimate & Unstandardized & Standardized & $\mathrm{p}$ \\
\hline \multicolumn{4}{|l|}{ Measurement Model Estimates } \\
\hline Relationship Quality $\rightarrow \mathrm{P}^{\mathrm{a}}$ Behavioral & 1.00 & .68 & .00 \\
\hline Relationship Quality $\rightarrow \mathrm{R}^{\mathrm{b}}$ Behavioral & $.82(.09)$ & .50 & .00 \\
\hline Relationship Quality $\rightarrow$ P Evaluative & $1.03(.09)$ & .75 & .00 \\
\hline Relationship Quality $\rightarrow$ R Evaluative & $.70(.08)$ & .44 & .00 \\
\hline Denomination Similarity $\rightarrow$ Relationship & $.04(.21)$ & .01 & .86 \\
\hline \multicolumn{4}{|l|}{ Quality } \\
\hline JRA $\rightarrow$ R Religion Together & 1.00 & .73 & .00 \\
\hline JRA $\rightarrow$ P Religion Together & $1.27(.07)$ & .90 & .00 \\
\hline JRA $\rightarrow$ R Pray Together & $.93(.05)$ & .63 & .00 \\
\hline JRA $\rightarrow$ P Pray Together & $1.02(.06)$ & .73 & .00 \\
\hline Error in P Behavioral & $6.17(.57)$ & & .00 \\
\hline Error in $\mathrm{R}$ Behavioral & $10.93(.73)$ & & .00 \\
\hline Error in P Evaluative & $4.54(.53)$ & & .00 \\
\hline Error in R Evaluative & $10.99(.71)$ & & .00 \\
\hline Error in R Religion Together & $1.14(.09)$ & & .00 \\
\hline Error in P Religion Together & $.53(.09)$ & & .00 \\
\hline Error in R Pray Together & $1.70(.11)$ & & .00 \\
\hline Error in P Pray Together & $1.21(.09)$ & & .00 \\
\hline Covariance P Evaluative and $\mathrm{R}$ & $3.13(.55)$ & . & .00 \\
\hline \multicolumn{4}{|l|}{ Evaluative } \\
\hline Covariance R Religion Together and R & $.62(.07)$ & & .00 \\
\hline \multicolumn{4}{|l|}{ Pray Together } \\
\hline Covariance R Pray Together and P Pray & $.48(.07)$ & & .00 \\
\hline Together & & & \\
\hline \multicolumn{4}{|l|}{ Structural Model Estimates } \\
\hline $\begin{array}{l}\text { Religious Similarity } \rightarrow \text { Relationship } \\
\text { Quality }\end{array}$ & $.36(.26)$ & .06 & .17 \\
\hline $\begin{array}{l}\text { Religious Similarity } \rightarrow \text { Joint Religious } \\
\text { Activities }\end{array}$ & $.05(.13)$ & .02 & .67 \\
\hline $\begin{array}{l}\text { Joint Religious Activities } \rightarrow \\
\text { Relationship Quality }\end{array}$ & $.91(.12)$ & .45 & .00 \\
\hline
\end{tabular}

Note: $\chi^{2}(30)=135.5, p<.00 ; \mathrm{CFI}=.94 ; \mathrm{RMSEA}=.07$. ${ }^{\mathrm{a}} \mathrm{P}=$ Partner responses. ${ }^{\mathrm{b}} \mathrm{R}=$

Respondent responses. 
Table 5

Unstandardized Estimates, Standardized Estimates, and Significance Levels for

Hypothesized Social Support Mediation (Standard Errors in Parentheses; $N=621$ )

\begin{tabular}{llll}
\hline Parameter Estimate & Unstandardized & Standardized & $p$
\end{tabular}

Measurement Model Estimates

Relationship Quality $\rightarrow \mathrm{P}^{\mathrm{a}}$ Behavioral

Relationship Quality $\rightarrow \mathrm{R}^{\mathrm{b}}$ Behavioral

1.00

$.85(.09)$

$1.12(.11)$

$.73(.09)$

$.63(.21)$

Relationship Quality $\rightarrow$ R Evalu
Denominational Similarity $\rightarrow$

Relationship Quality

Social Support $\rightarrow$ P Contact

Social Support $\rightarrow$ R Contact

Social Support $\rightarrow$ P Volunteer

Social Support $\rightarrow$ R Volunteer

Social Support $\rightarrow$ P Money

Social Support $\rightarrow$ R Money

Error in P Behavioral

Error in R Behavioral

Error in P Evaluative

Error in R Evaluative

Error in P Contact

Error in R Contact

Error in $\mathrm{P}$ Volunteer

Error in R Volunteer

Error in P Money

Error in R Money

Covariance $\mathrm{R}$ Behavioral and $\mathrm{R}$

Evaluative

Covariance P Contact and P Volunteer
1.00

$.96(.25)$

$.64(.17)$

$.94(.26)$

$2.18(.46)$

$1.75(.37)$

$6.58(.60)$

$11.01(.74)$

$4.06(.62)$

$10.96(.71)$

$1.90(.11)$

$1.74(.10)$

$.93(.06)$

$1.91(.11)$

$.87(.12)$

$.62(.07)$

$3.15(.56)$

$.21(.07)$
.00

.00

.00

.00

$.14 \quad .00$

$.27 \quad .00$

$.27 \quad .00$

$.25 \quad .00$

$.25 \quad .00$

$.67 \quad .00$

$.65 \quad .00$

.00

.00

.00

.00

.00

.00

.00

.00

.00

.00

.00

.00

Structural Model Estimates

Religious Similarity $\rightarrow$ Relationship $\quad .36(.27) \quad \quad .07 \quad .17$ Quality

Religious Similarity $\rightarrow$ Social Support $\quad .04(.05) \quad .049$

Social Support $\rightarrow$ Relationship Quality

$1.06(.40)$

.18

.00

Note: $\chi^{2}(50)=155.34, p<.00 ; \mathrm{CFI}=.86$; RMSEA $=.06 .{ }^{\mathrm{a}} \mathrm{P}=$ Partner responses. ${ }^{\mathrm{b}} \mathrm{R}=$

Respondent responses. 
Table 6

Unstandardized Estimates, Standardized Estimates, and Significance Levels for Modified Social Support Mediation (Standard Errors in Parentheses; $N=621$ )

\begin{tabular}{llll}
\hline Parameter Estimate & Unstandardized & Standardized
\end{tabular}

\begin{tabular}{|c|c|c|c|}
\hline \multicolumn{4}{|l|}{ Measurement Model Estimates } \\
\hline Relationship Quality $\rightarrow \mathrm{P}^{\mathrm{a}}$ Behavioral & 1.00 & .66 & .00 \\
\hline Relationship Quality $\rightarrow \mathrm{R}^{\mathrm{b}}$ Behavioral & $.84(.09)$ & .49 & .00 \\
\hline Relationship Quality $\rightarrow$ P Evaluative & $1.12(.11)$ & .78 & .00 \\
\hline Relationship Quality $\rightarrow$ R Evaluative & $.74(.09)$ & .44 & .00 \\
\hline Denominational Similarity $\rightarrow$ & $.56(.21)$ & .13 & .01 \\
\hline \multicolumn{4}{|l|}{ Relationship Quality } \\
\hline Social Support $\rightarrow$ Money Average & 1.00 & .40 & .00 \\
\hline Social Support $\rightarrow$ Volunteer Average & $.99(.25)$ & .45 & .00 \\
\hline Social Support $\rightarrow$ Contact Average & $1.50(.39)$ & .54 & .00 \\
\hline Error in P Behavioral & $6.59(.60)$ & & .00 \\
\hline Error in $\mathrm{R}$ Behavioral & $11.03(.74)$ & & .00 \\
\hline Error in P Evaluative & $4.07(.62)$ & & .00 \\
\hline Error in R Evaluative & $10.93(.71)$ & & .00 \\
\hline Error in Money Average & $.80(.07)$ & & .00 \\
\hline Error in Volunteer Average & $.61(.06)$ & & .00 \\
\hline Error in Contact Average & $.84(.11)$ & & .00 \\
\hline Covariance R Behavioral and R & $3.14(.56)$ & . & .00 \\
\hline \multicolumn{4}{|l|}{ Evaluative } \\
\hline \multicolumn{4}{|l|}{ Structural Model Estimates } \\
\hline $\begin{array}{l}\text { Religious Similarity } \rightarrow \text { Relationship } \\
\text { Quality }\end{array}$ & $.35(.27)$ & .06 & .20 \\
\hline Religious Similarity $\rightarrow$ Social Support & $.04(.06)$ & .04 & .50 \\
\hline Social Support $\rightarrow$ Relationship Quality & $1.43(.49)$ & .25 & .00 \\
\hline
\end{tabular}


Table 7

Unstandardized Estimates, Standardized Estimates, and Significance Levels for Joint

Religious Activities Mediation Model with Respondents' Perceived Similarity (Standard

Errors in Parentheses; $N=621$ )

Parameter Estimate

Unstandardized Standardized

$\mathrm{p}$

\begin{tabular}{|c|c|c|c|}
\hline \multicolumn{4}{|l|}{ Measurement Model Estimates } \\
\hline Relationship Quality $\rightarrow \mathrm{P}^{\mathrm{a}}$ Behavioral & 1.00 & .68 & .00 \\
\hline Relationship Quality $\rightarrow \mathrm{R}^{\mathrm{b}}$ Behavioral & $.82(.09)$ & .50 & .00 \\
\hline Relationship Quality $\rightarrow$ P Evaluative & $1.04(.10)$ & .75 & .00 \\
\hline Relationship Quality $\rightarrow$ R Evaluative & $.70(.08)$ & .44 & .00 \\
\hline Denominational Similarity $\rightarrow$ & $.03(.21)$ & .01 & .88 \\
\hline \multicolumn{4}{|l|}{ Relationship Quality } \\
\hline JRA $\rightarrow$ R Religion Together & 1.00 & .73 & .00 \\
\hline JRA $\rightarrow$ P Religion Together & $1.27(.07)$ & .90 & .00 \\
\hline JRA $\rightarrow$ R Pray Together & $.93(.05)$ & .63 & .00 \\
\hline JRA $\rightarrow$ P Pray Together & $1.02(.06)$ & .73 & .00 \\
\hline Error in $\mathrm{P}$ Behavioral & $6.18(.57)$ & & .00 \\
\hline Error in R Behavioral & $10.91(.73)$ & & .00 \\
\hline Error in P Evaluative & $4.54(.53)$ & & .00 \\
\hline Error in R Evaluative & $10.97(.71)$ & & .00 \\
\hline Error in R Religion Together & $1.14(.09)$ & & .00 \\
\hline Error in P Religion Together & $.53(.09)$ & & .00 \\
\hline Error in R Pray Together & $1.70(.11)$ & & .00 \\
\hline Error in P Pray Together & $1.21(.09)$ & & .00 \\
\hline Covariance $\mathrm{R}$ Behavioral and $\mathrm{R}$ & $3.11(.55)$ & . & .00 \\
\hline \multicolumn{4}{|l|}{ Evaluative } \\
\hline Covariance R Religion Together and R & $.62(.07)$ & & .00 \\
\hline \multicolumn{4}{|l|}{ Pray Together } \\
\hline Covariance R Pray Together and P Pray & $.48(.07)$ & & .00 \\
\hline \multicolumn{4}{|l|}{ Together } \\
\hline \multicolumn{4}{|l|}{ Structural Model Estimates } \\
\hline $\begin{array}{c}\text { R Perception of Similarity } \rightarrow \\
\text { Relationship Quality }\end{array}$ & $-.01(.11)$ & .00 & .95 \\
\hline $\begin{array}{l}\text { R Perception of Similarity } \rightarrow \text { Joint } \\
\text { Religious Activities }\end{array}$ & $-.01(.05)$ & -.01 & .81 \\
\hline $\begin{array}{l}\text { Joint Religious Activities } \rightarrow \\
\text { Relationship Quality }\end{array}$ & $.91(.12)$ & .45 & .00 \\
\hline
\end{tabular}


Note: $\chi^{2}(30)=138.62, p<.00 ; \mathrm{CFI}=.94 ; \mathrm{RMSEA}=.07 .{ }^{\mathrm{a}} \mathrm{P}=$ Partner estimates. ${ }^{\mathrm{b}} \mathrm{R}=$ Respondent responses. 
Table 8

Unstandardized Estimates, Standardized Estimates, and Significance Levels for Joint

Religious Activities Mediation Model with Partners' Perceived Similarity (Standard

Errors in Parentheses; $N=621$ )

\begin{tabular}{|c|c|c|c|}
\hline Parameter Estimate & Unstandardized & Standardized & $\mathrm{p}$ \\
\hline \multicolumn{4}{|l|}{ Measurement Model Estimates } \\
\hline Relationship Quality $\rightarrow \mathrm{P}^{\mathrm{a}}$ Behavioral & 1.00 & .68 & .00 \\
\hline Relationship Quality $\rightarrow \mathrm{R}^{\mathrm{b}}$ Behavioral & $.83(.09)$ & .50 & .00 \\
\hline Relationship Quality $\rightarrow$ P Evaluative & $1.05(.10)$ & .75 & .00 \\
\hline Relationship Quality $\rightarrow$ R Evaluative & $.71(.09)$ & .44 & .00 \\
\hline Denominational Similarity $\rightarrow$ & $.01(.21)$ & .00 & .96 \\
\hline \multicolumn{4}{|l|}{ Relationship Quality } \\
\hline JRA $\rightarrow$ R Religion Together & 1.00 & .73 & .00 \\
\hline JRA $\rightarrow$ P Religion Together & $1.26(.07)$ & .89 & .00 \\
\hline JRA $\rightarrow$ R Pray Together & $.93(.05)$ & .63 & .00 \\
\hline JRA $\rightarrow$ P Pray Together & $1.02(.06)$ & .73 & .00 \\
\hline Error in P Behavioral & $6.26(.56)$ & & .00 \\
\hline Error in $\mathrm{R}$ Behavioral & $10.89(.73)$ & & .00 \\
\hline Error in P Evaluative & $4.48(.53)$ & & .00 \\
\hline Error in R Evaluative & $10.94(.71)$ & & .00 \\
\hline Error in R Religion Together & $1.13(.09)$ & & .00 \\
\hline Error in P Religion Together & $.54(.09)$ & & .00 \\
\hline Error in R Pray Together & $1.69(.11)$ & & .00 \\
\hline Error in P Pray Together & $1.20(.09)$ & & .00 \\
\hline Covariance $\mathrm{R}$ Behavioral and $\mathrm{R}$ & $3.08(.55)$ & . & .00 \\
\hline \multicolumn{4}{|l|}{ Evaluative } \\
\hline Covariance R Religion Together and R & $.62(.07)$ & & .00 \\
\hline Pray Together & & & \\
\hline $\begin{array}{l}\text { Covariance R Pray Together and P Pray } \\
\text { Together }\end{array}$ & $.48(.07)$ & & .00 \\
\hline \multicolumn{4}{|l|}{ Structural Model Estimates } \\
\hline $\begin{array}{c}\text { P Perception of Similarity } \rightarrow \\
\text { Relationship Quality }\end{array}$ & $.15(.13)$ & .05 & .24 \\
\hline $\begin{array}{c}\text { P Perception of Similarity } \rightarrow \text { Joint } \\
\text { Religious Activities }\end{array}$ & $.15(.06)$ & .11 & .02 \\
\hline $\begin{array}{l}\text { Joint Religious Activities } \rightarrow \\
\text { Relationship Quality }\end{array}$ & $.90(.12)$ & .45 & .00 \\
\hline
\end{tabular}


Note: $\chi^{2}(30)=142.91, p<.00 ; \mathrm{CFI}=.94 ; \mathrm{RMSEA}=.07 .{ }^{\mathrm{a}} \mathrm{P}=$ Partner responses. ${ }^{\mathrm{b}} \mathrm{R}=$ Respondent responses. 
Table 9

Unstandardized Estimates, Standardized Estimates, and Significance Levels for Modified Social Support Mediation Model with Respondents' Perceived Similarity (Standard

Errors in Parentheses; $N=621$ )

\begin{tabular}{|c|c|c|c|}
\hline Parameter Estimate & Unstandardized & Standardized & $\mathrm{p}$ \\
\hline \multicolumn{4}{|l|}{ Measurement Model Estimates } \\
\hline Relationship Quality $\rightarrow \mathrm{P}^{\mathrm{a}}$ Behavioral & 1.00 & .65 & .00 \\
\hline Relationship Quality $\rightarrow \mathrm{R}^{\mathrm{b}}$ Behavioral & $.85(.09)$ & .49 & .00 \\
\hline Relationship Quality $\rightarrow$ P Evaluative & $1.12(.11)$ & .78 & .00 \\
\hline Relationship Quality $\rightarrow$ R Evaluative & $.74(.09)$ & .45 & .00 \\
\hline Denominational Similarity $\rightarrow$ & $.55(.21)$ & .12 & .01 \\
\hline \multicolumn{4}{|l|}{ Relationship Quality } \\
\hline Social Support $\rightarrow$ Money Average & 1.00 & .39 & .00 \\
\hline Social Support $\rightarrow$ Volunteer Average & $1.00(.25)$ & .44 & .00 \\
\hline Social Support $\rightarrow$ Contact Average & $1.59(.42)$ & .56 & .00 \\
\hline Error in $\mathrm{P}$ Behavioral & $6.60(.60)$ & & .00 \\
\hline Error in R Behavioral & $11.01(.74)$ & & .00 \\
\hline Error in P Evaluative & $4.08(.62)$ & & .00 \\
\hline Error in $\mathrm{R}$ Evaluative & $10.90(.71)$ & & .00 \\
\hline Error in Money Average & $.81(.07)$ & & .00 \\
\hline Error in Volunteer Average & $.61(.06)$ & & .00 \\
\hline Error in Contact Average & $.82(.11)$ & & .00 \\
\hline Covariance $\mathrm{R}$ Behavioral and $\mathrm{R}$ & $3.11(.56)$ & . & .00 \\
\hline \multicolumn{4}{|l|}{ Evaluative } \\
\hline \multicolumn{4}{|l|}{ Structural Model Estimates } \\
\hline $\begin{array}{c}\text { R Perception of Similarity } \rightarrow \\
\text { Relationship Quality }\end{array}$ & $.02(.11)$ & .01 & .83 \\
\hline $\begin{array}{l}\text { R Perception of Similarity } \rightarrow \text { Social } \\
\text { Support }\end{array}$ & $-.02(.02)$ & -.06 & .39 \\
\hline Social Support $\rightarrow$ Relationship Quality & $1.49(.50)$ & .26 & .00 \\
\hline
\end{tabular}


Table 10

Unstandardized Estimates, Standardized Estimates, and Significance Levels for Modified Social Support Mediation Model with Partners' Perceived Similarity (Standard Errors in Parentheses; $N=621$ )

\begin{tabular}{|c|c|c|c|}
\hline Parameter Estimate & Unstandardized & Standardized & $\mathrm{p}$ \\
\hline \multicolumn{4}{|l|}{ Measurement Model Estimates } \\
\hline Relationship Quality $\rightarrow \mathrm{P}^{\mathrm{a}}$ Behavioral & 1.00 & .65 & .00 \\
\hline Relationship Quality $\rightarrow \mathrm{R}^{\mathrm{b}}$ Behavioral & $.86(.09)$ & .50 & .00 \\
\hline Relationship Quality $\rightarrow$ P Evaluative & $1.14(.12)$ & .78 & .00 \\
\hline Relationship Quality $\rightarrow$ R Evaluative & $.75(.09)$ & .45 & .00 \\
\hline Denominational Similarity $\rightarrow$ & $.51(.21)$ & .12 & .02 \\
\hline \multicolumn{4}{|l|}{ Relationship Quality } \\
\hline Social Support $\rightarrow$ Money Average & 1.00 & .41 & .00 \\
\hline Social Support $\rightarrow$ Volunteer Average & $1.02(.25)$ & .46 & .00 \\
\hline Social Support $\rightarrow$ Contact Average & $1.45(.37)$ & .53 & .00 \\
\hline Error in $\mathrm{P}$ Behavioral & $6.69(.59)$ & & .00 \\
\hline Error in R Behavioral & $11.00(.74)$ & & .00 \\
\hline Error in P Evaluative & $4.00(.62)$ & & .00 \\
\hline Error in $\mathrm{R}$ Evaluative & $10.87(.71)$ & & .00 \\
\hline Error in Money Average & $.80(.07)$ & & .00 \\
\hline Error in Volunteer Average & $.60(.06)$ & & .00 \\
\hline Error in Contact Average & $.86(.10)$ & & .00 \\
\hline Covariance $\mathrm{R}$ Behavioral and $\mathrm{R}$ & $3.09(.55)$ & . & .00 \\
\hline \multicolumn{4}{|l|}{ Evaluative } \\
\hline \multicolumn{4}{|l|}{ Structural Model Estimates } \\
\hline $\begin{array}{c}\text { P Perception of Similarity } \rightarrow \\
\text { Relationship Quality }\end{array}$ & $.28(.13)$ & .10 & .04 \\
\hline $\begin{array}{l}\text { P Perception of Similarity } \rightarrow \text { Social } \\
\text { Support }\end{array}$ & $-.02(.03)$ & -.04 & .50 \\
\hline Social Support $\rightarrow$ Relationship Quality & $1.44(.49)$ & .26 & .00 \\
\hline
\end{tabular}


VITA

Ashlie Lester has been interested in the intersection of religion and family life for much of her life, and she plans to continue this line of research in the future. 